\title{
My cattle and your park: codesigning a role-playing game with rural communities to promote multistakeholder dialogue at the edge of protected
}

\section{areas}

Arthur Perrotton $^{1,2}$, Michel de Garine-Wichatitsky $^{1,3,4}$, Hugo Valls-Fox $^{5}$ and Christophe Le Page ${ }^{6}$

\begin{abstract}
Protected areas are often burdened with conflicts between environmental managers and neighboring rural communities. Unsuccessful top-down approaches for conservation may be replaced by alternative forms of systemic management involving local actors in the design and implementation of conservation management. Although theoretically sound and appealing, the involvement of local residents in the management of protected areas is often impaired in practice by scale mismatches, conflicting values and interests, power imbalance, and a lack of trust among actors. In this paper, we describe a process initiated in Zimbabwe to create a fair and balanced locally designed arena where local communities and protected area managers may collaborate to produce effective management plans. Adopting the Companion Modeling approach, we conducted a participatory modeling experiment to codesign a role-playing game that simulates the interactions between farming activities, livestock herding practices, and wildlife in a virtual landscape reproducing local social-ecological dynamics. After 18 months of intensive ethnographical fieldwork to gain knowledge and legitimacy, we spent one year codesigning the first version of the game with a group of volunteer villagers. The game, called Kulayijana (teaching each other), was tested and validated by other members of the rural communities and subsequently presented to protected area managers. We show how this approach allowed the negotiation of uncertainties and their inclusion in a model that constitutes a shared representation of farmers' interactions with the protected area. We emphasize the fact that working with marginalized actors first increased participation, appropriation, and confidence of rural communities to engage in a multistakeholder debate, thus reducing power imbalance among actors. We conclude by discussing the next phase of our work: the necessary involvement of conservation actors in the Kulayijana team, and the implementation of Kulayijana with higher hierarchical levels.
\end{abstract}

Key Words: coexistence; multistakeholder; participatory modeling; role-playing game; Zimbabwe

\section{INTRODUCTION}

Protected areas have been widely used as a strategy for conserving biodiversity in the face of ecosystem degradation (Palomo et al. 2014). However, like any other efforts to protect the environment, they are often associated with conflicts between local actors (Wittmer et al. 2006), including illegal hunting (Rowcliffe et al. 2004), human-wildlife conflicts (Dublin and Hoare 2004, Guerbois et al. 2012, Dickman et al. 2014, Lyamuya et al. 2014, Chitakira et al. 2015, Constant et al. 2015, Matema and Andersson 2015), coercion and violence toward local populations (Duffy 2014), and the symmetrical, sometimes violent, protest of local populations to conservation policies (Newmark and Hough 2000, Orlove 2002, Stern 2008). Protests are fueled by past and present social violence experienced by people living on the edges of protected areas. As pointed out for instance by Agrawal and Ostrom (2001), the creation of protected areas alters land-use rights, leading to the alienation of land from the original users and their criminalization (Ncube 2004, West et al. 2006). Topdown approaches of conservation implemented by states have failed to appreciate local practices and interests and have often ignored the fact that local communities are shouldering the cost of conserving a global public goods (Brockington and Wilkie 2015). This was summarized in the Durban Action Plan produced after the fifth World Park Congress (International Union for Conservation of Nature 2003), which states that there are connections between dispossession and poverty, culture change and social subsistence losses on the part of people living around protected areas (MacKay and Carison 2004). As an answer to the struggle to enforce conservation policies, protected areas are increasingly being militarized (Duffy 2014, Verweijen and Marijnen 2016).

Over the last three decades, several alternative forms of management have emerged to replace the adversarial and centralized enforcement of conservation policies. Adaptive management (Allen and Garmestani 2015), collaborative management (Ansell and Gash 2008), and adaptive comanagement (Fabricius and Currie 2015) share common conceptual underpinnings of the social-ecological system framework (McGinnis and Ostrom 2014). They first acknowledge the need to consider both local ecological and social dynamics (Mathevet et al. 2016) and the necessity of adopting interdisciplinary approaches. They also acknowledge the inherent uncertainties and unpredictability of social-ecological dynamics (Dewulf et al. 2005, Brugnach et al. 2008, Allen and Gunderson 2011). When uncertainty results from a lack of scientific knowledge, these new forms of management use the participation of local actors in "extended peer communities" (Funtowicz and Ravetz 1993) for expert knowledge and local knowledge to be shared and mixed (Allen and Gunderson 2011). In other words,

${ }^{1}$ Centre de coopération internationale en recherche agronomique pour le développement (CIRAD), UR AGIRs, ${ }^{2}$ Center for Applied Social Sciences (CASS), University of Harare, Zimbabwe, ${ }^{3}$ Department of Biological Sciences, University of Zimbabwe, Harare, Zimbabwe, ${ }^{4} \mathrm{Current}$ address: Faculty of Veterinary Medicine, Kasetsart University, Bangkok, Thailand, ${ }^{5}$ Centre d'Ecologie Fonctionnelle et Evolutive, UMR 5175, Centre National de la Recherche Scientifique (CNRS), Université de Montpellier, Université Paul Valéry Montpellier, Ecole Pratiques des Hautes Etudes (EPHE), ${ }^{6}$ CIRAD GREEN 
participation is seen as a way to increase knowledge, which in turn reduces uncertainties. These approaches rely on the assumption that participatory management of renewable resources is more efficient because decisions, actions, and consequences occur at the same scale (Cinner et al. 2012). Finally, they propose the adoption of a cyclical iterative process through which local actors define objectives, implement them, and learn (Fabricius and Currie 2015).

Although these concepts are promising and theoretically sound, their implementation in natural resource management has failed more often than not (Allen and Gunderson 2011). Among the factors explaining such failure is the fact that the involvement of local residents, one of their core ideas, is still controversial (Mannigel 2008). As pointed by Cumming et al. (2013), international treaties and conventions frame conservation policies, and these agreements have been translated and implemented at the national scale. However, the implementation of management decisions takes place at the local level and depends on local resources. Yet, the feedbacks from local levels are always weaker than the constraints imposed by higher levels. As a result, collaborative management involving local rural communities, local managers, and international conventions is hardly possible. This situation is a typical "scale mismatch" among institutional, management, ecological, and social dynamics (Maciejewski et al. 2014). As expressed by Wells and McShane (2004), if protected areas have limited prospects without cooperation and support from local people, any form of collective management implies navigating through multiple and equally valid framings of a given issue (Dewulf et al. 2005). These multiple framings result in ambiguities and misunderstandings between actors (Brugnach et al. 2008), not to mention the potential conflicting values and perspectives brought in by the stakeholders (Balint 2011, Curtin 2014). Finally, a true and sustainable collaboration between actors is difficult to implement considering the accumulation of historical injustice inherent to the establishment of many protected areas (West et al. 2006, Andersson et al. 2013b), power imbalances between rural communities and governmental environment management authorities (Ansell and Gash 2008, Crane et al. 2009), and the resultant lack of trust between these actors (Stern 2008).

In this paper, we describe the first step of a long-term project in western Zimbabwe addressing some of the pitfalls described earlier. We aim to create a fair and balanced locally designed arena where local communities and protected area managers can meet, discuss, negotiate, and produce effective management plans. Adopting the companion modeling (ComMod) approach, we conducted a participatory modeling experiment with rural communities to codesign an interactive model simulating interactions between farming activities, livestock herding, and wildlife in a virtual landscape. Unlike most other ComMod processes described in the literature, prior to the design of the actual model, 18 months were dedicated to an immersive ethnographic fieldwork among local communities to gather a detailed understanding of the social-ecological context. It appeared that cattle crystalizes tensions between rural communities and protected areas in the study area. Such a long preliminary phase also enabled us to build trust and acquire the legitimacy needed by researchers to act as facilitators in the ComMod process. First, we present the approach and the study area, then we provide details about the codesign of the role- playing game with a small group of local farmers. We explain how we obtained feedback to assess the codesigners' perceptions of this participatory process. To validate the game, we analyze three sessions that were organized with other local farmers. Finally, we describe how the game was also tested by a group of protected areas managers, before discussing the lessons drawn from the process and the challenges to be met in the next stages.

\section{THE SIKUMI-HWANGE SOCIAL-ECOLOGICAL SYSTEM: ACTORS AND LAND USE}

\section{History of coexistence in the area}

The study area is located in the Kalahari sand dune system of southern Africa (Stokes et al. 1997). This work was conducted in the villages of Magoli, Siyalwindi, Chezhou, Dingani, and Jwape within ward 15 of the Hwange District, western Zimbabwe (26.9 E, $18.6^{\circ} \mathrm{S}$; Fig. 1). The study area receives between 450 and 650 $\mathrm{mm}$ of rain per year and is characterized by the presence of dry spells and droughts, which added to poor soils make this area poorly suited to agriculture (Matarira and Jury 1992). Villages are restricted to the communal area, which is dedicated to human settlements with land allocated by traditional authorities (Guerbois et al. 2013). Rural populations rely mainly on subsistence agriculture. Maize, millet, and sorghum are the main food crops, and some households own livestock (Andersson et al. $2013 a$ ). The villages neighbor two unfenced protected areas, Hwange National Park $\left(14.651 \mathrm{~km}^{2}\right)$, a wildlife conservation and tourism area located a few kilometers to the southwest, and Sikumi Forest $\left(1100 \mathrm{~km}^{2}\right)$, a wildlife conservation, wildlife-based tourism (seven lodges in the study area) and timber production area adjacent to the communal land separated from the villages by a single-lane tar road. Coexistence issues at the interface between Hwange National Park, Sikumi Forest, and rural populations include human-wildlife conflicts (Metcalfe and Kepe 2008), illegal hunting (Muboko et al. 2014), cattle incursions into restricted protected areas, illegal wood harvesting, livestock predation by wild carnivores, and crop raiding by wildlife (Guerbois et al. 2012), along with disease transmission between domestic livestock and wildlife (de Garine-Wichatitsky et al. 2013).

Fig. 1. Study area, villages adjacent to Hwange National Park and Sikumi Forest, Zimbawe.

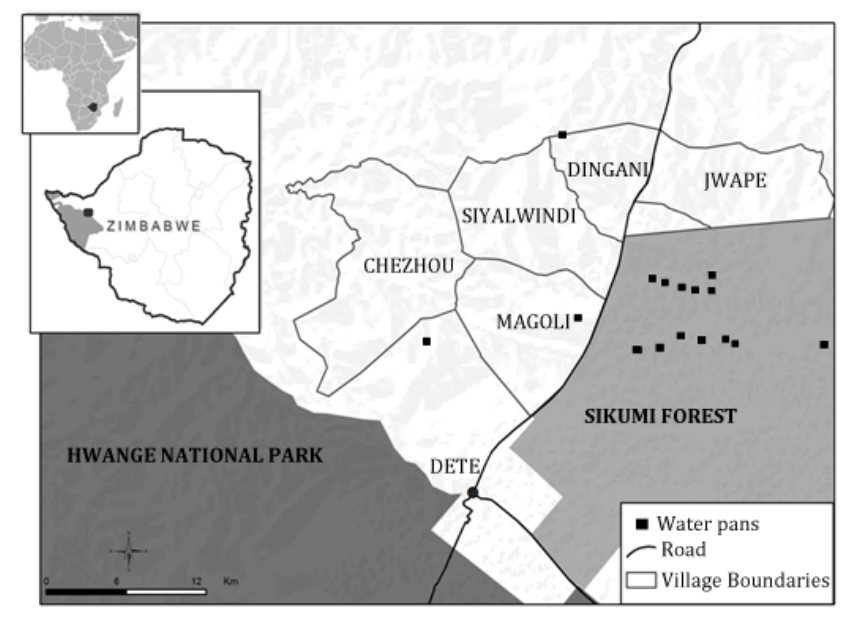


Interactions between protected and communal areas have been shaped by colonial and postindependence history. Local communities have been evicted and resettled on two occasions by the creation of the Wankie Game Reserve in 1928 and the proclamation of Sikumi Forest in 1968 (Ncube 2004). Since then, local communities have no right of access to Hwange National Park for any natural resources use/extraction, except for the occasional harvesting of thatching grass under the close supervision of rangers. The severe droughts of the early 1990s (Maphosa 1994) led the forestry commission and traditional leaders to negotiate a right of access to the Sikumi forest for neighboring communities. Herders obtained the right to graze their cattle within the forest (Ncube 2004, Guerbois et al. 2013), although the official authorized distance remains unclear and, depending on the informant, ranges from $2-3 \mathrm{~km}$ according to a forestry manager (Guerbois et al. 2013), and up to $7 \mathrm{~km}$ according to local herders. This right of access is a bone of contention between traditional leaders and the forestry commission.

\section{An ethnography of cattle-herding practices}

Ethnographic fieldwork and analyses were conducted to understand how cattle management was instrumental in shaping coexistence between the protected area and neighboring communities. Semidirected interviews and open discussions were carried out with livestock owners and herders on the one hand and with protected areas managers on the other. Interviews were conducted in three different languages: English and the two major local languages, chiNambya and sinNdebele. These were completed with direct observations (e.g., participation in cattle herding and other agricultural activity). We also had access to livestock census books kept by traditional leaders. The next paragraph presents the main findings of our observations, and shows how cattle herding is at the core of interactions between the different land uses, therefore justifying our decision to design a game on cattle-related practices.

Based on local records, only $32 \%$ of homesteads living in the study area own cattle. On average, these families have 5.46 cattle ( $\mathrm{sd}=$ 4.19). Livestock is nevertheless central to agricultural production, and draft animals are often borrowed or sometimes rented, strengthening social cohesion amongst neighbors. Livestock is the main form of capitalization for rural populations. Beyond their agricultural value, cattle also have a social dimension through the payment of the bride price, locally called "lobola." Although foraging resources are a crucial driver, the cattleherding calendar is largely determined by agricultural practices (Perrotton 2015, Valls-Fox 2015). The agricultural calendar depends on weather patterns both on a large and a fine scale as plowing strategies are revised almost daily by local farmers. We can broadly distinguish three phases of cattle grazing. During the cropping season (November-May), herders maintain cattle away from fields to minimize incursions and resulting damages to crops. Not every owner sends his cows into Sikumi Forest, and some favor the communal grazing areas to reduce predation risk. Cattle herded out of the communal area feed approximately from 11:00 a.m. to 4:00 p.m. in the forest, and natural water pans shape the herding movements. Each year, traditional leaders define the "xotshela," meaning "release" in sinNdebele, giving the date after which livestock are allowed to roam freely in the communal area. Once the date is chosen, farmers must make sure all their fields are harvested in time. After "xotshela," cows are no longer herded and roam freely in the fields, feeding on grass and crop residues. However, they must be taken to the communal dams or to boreholes to drink. Part of the crop residues are often stored within the homestead to feed cows later on. Toward the beginning of the hot and dry season, usually the end of August, cattle start going unguarded in the forest as available fodder becomes too scarce in the communal area. During this period, they usually go foraging further inside the forest, and herders are often forced to retrieve them, sometimes more than $7 \mathrm{~km}$ away from the boundary of the Sikumi Forest. This is a general pattern for the majority of cattle herds, but on an individual scale, cattle-herding strategies are complex mechanisms that involve personal histories of owners and herd-boys, a permanent consideration of dynamic environmental parameters, the proximity of homesteads to the forest, and neighbors' strategies. The right of access to the forestry's land is crucial for livestock owners and simultaneously constitutes a form of land claiming on a territory that used to be owned by the villagers.

Although they were not involved in the codesign of the simulation tool described in the next session, we also spent time with local conservation actors during this preliminary stage of the participatory process. Interviews with protected areas managers highlighted the complexity of management issues linked with coexistence. Hwange National Park and the Sikumi Forest are two conservation areas managed by government agencies, but they have established different relationships with the surrounding communities. Hwange National Park is dedicated to conservation and tourism. From its creation, the park had limited interactions with rural communities, except for occasional "community awareness" meetings during which authorities deliver the conservationist dogma to villagers, or when National Parks scouts are sent to deter elephants and other wild animals away from villages. Conflictive encounters with wildlife are frequent, although these are rarely made public. When caught grazing inside the park, cattle are impounded and released after payment of a fine by the owner. Like other African countries, policies against illegal hunting involve a shoot-to-kill approach (Duffy 2000, 2014), and the recent use of cyanide to illegally hunt elephants (Muboko et al. 2014) or the illegal killing of Cecil the lion in a neighboring hunting concession (Nelson et al. 2016) did not push for a change. Sikumi Forest has completely different relationships with rural communities. As we wrote in a previous paragraph, natural resources within the forest are partly available to villagers: grazing, thatching grass, construction poles (after a permit is delivered by the local traditional authority and signed by the local forestry manager), and firewood (only gathered by women on Thursdays). In addition to providing natural resources, Sikumi Forest sustains social relationships between local actors. Nevertheless, several issues remain unsolved.

We know they need to enter our forest, that's why we are flexible with them. But they go too far inside and create problems for us. (A forestry manager, Sikumi, 2013.)

As stated above, although forestry managers support a policy of letting community members enter under strict rules, this agreement is the source of various concerns, among which are overgrazing to the detriment of wildlife and opportunistic extraction activities, such as illegal wood harvesting or hunting, and disturbance of tourism activities taking place in Sikumi Forest only a few kilometers away from the villages. 
Fig. 2. Codesign of the role-playing game through an iterative process. Each workshop provides new elements or modifications that researchers use to improve the model/game. Each set of modifications is tested in the following workshop in order to validate the changes made (e.g., Souchère et al. 2010).

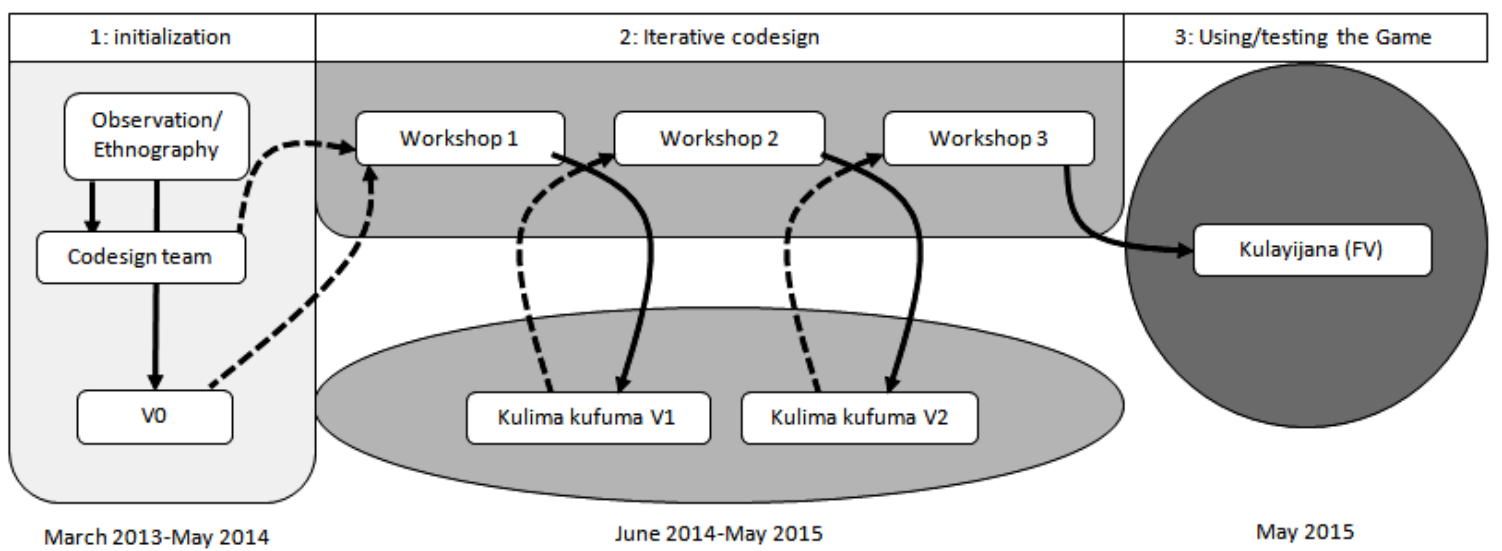

Tensions around cattle at the interface between the protected areas and neighboring rural community are typical of "wicked problems" (Balint 2011): uncertainty (climate, resources availability), incomplete scientific knowledge (e.g., how do herders drive cattle? What is the vegetation composition in the forest? How do cattle impact vegetation in the forest?), ambiguity maintained by local actors (what is the legal right of access?), competing cultural values (rural livelihood vs. wildlife conservation and timber production), and interconnections with other problems (unemployment, droughts). To address these wicked problems, we applied a postnormal approach (Funtowicz and Ravetz 2003) that promotes interdisciplinarity and participatory methods in social-ecological sciences. Over the past 10 years, the researchers involved in this study engaged in "research-action" programs to improve both conservation practices and rural livelihoods in Zimbabwe. Linking policy makers, extension services, and academics (social scientists, modelers, economists, epidemiologists, and ecologists), a research platform ("produce and conserve in partnership," see http://www. rp-pcp.org) was established. In recent years, a particular effort was made to involve farming communities in the research program and development activities.

\section{COMPANION MODELING: COLLECTIVE SENSE MAKING AND BOUNDARY OBJECTS}

The companion modeling (ComMod) approach (Bousquet et al. 1999, Étienne 2014) aims at identifying the various viewpoints and knowledge that local actors implicitly refer to and use in their relationships with their environment, working out - together with local stakeholders - a common vision of a given studied system in order to (i) understand its functioning or (ii) facilitate decisionmaking processes of stakeholders using a common resource.

ComMod processes have been conducted in various contexts in the past decades, such as land-use management in Senegal (d'Aquino et al. 2003, d'Aquino and Bah 2014), conflicts over water management in Thailand (Barnaud et al. 2006, 2008) and Bhutan (Gurung et al. 2006), collective awareness of sustainable use of reed beds (Mathevet et al. 2007), and hunting practices in African tropical forests (Le Page et al. 2015). The objects used for and produced through participation are "boundary objects" linking different actors belonging to different social worlds but involved in a common process (Vinck 2009, Queste et al. 2011). In ComMod, they often take the form of role-playing games or agent-based models. Among the fundamentals of ComMod are feedback loops between the models and reality. These loops constitute an iterative process (Fig. 2) during which the model is designed, tested, and redesigned with local actors. Each actor (researchers included) has his or her own mind-frame (Susskind et al. 2012) and his or her own sense-making process that mediate the interpretation of reality by adding meaning to a situation (Weick 1995). A ComMod process can then be considered as a collective sense-making process.

In our case, this collective sense making was initiated with a group composed of researchers and representatives of the rural communities. Although the ultimate goal is to build a boundary object to promote a multistakeholder dialogue, we did not involve all of these actors at once. Rural communities are marginalized when it comes to land management and conservation policies. We assumed that creating a fair and balanced multistakeholder arena first required the empowerment of rural communities. Creating the role-playing game with them first was our way to do so.

In our case, the boundary object is a role-playing game. In this paper, we'll use specific words that need to be explained, thus a set of definitions follows for the reader. Each definition is illustrated with an example from our role-playing game.

- Role-playing game: Technique or activity during which one plays the role of a character in a virtual environment. The player will influence the development of his character and the virtual environment through his physical and narrative actions, e.g., the role of a farmer.

- Module: The role-playing game is a form of model, with a virtual environment and characters interacting with it. As such, dynamics taking place during its use (playing sessions) rely on established rules/functions. These rules/functions can be grouped by type or topic. These sets are called "modules" and are small units structuring the game. In a computer- 
Fig. 3. Description of the prototype version of the role-playing game (V0): virtual environment (a), game setting (b) and rain calendar (c). a. The figure shows the virtual environment. The communal land (yellow) and the forest (green) are respectively composed of four and nine paddocks. Circles represent water pans (blue $=$ filled, white $=$ empty). Each farm is composed of a kraal (black) and five fields (orange). Each farm has a color; each herd has the color of its farm. Computerized farms are black and don't have any herd. b. The virtual environment was projected on the wall, and players had to come to the computer operator to signify their playing decisions. c. The four types of weekly weather were represented by explicit symbols: a sun for a dry weather with no rain, a light gray cloud for small rainfall, a dark gray cloud for medium rainfall, and a black cloud for heavy rainfall.

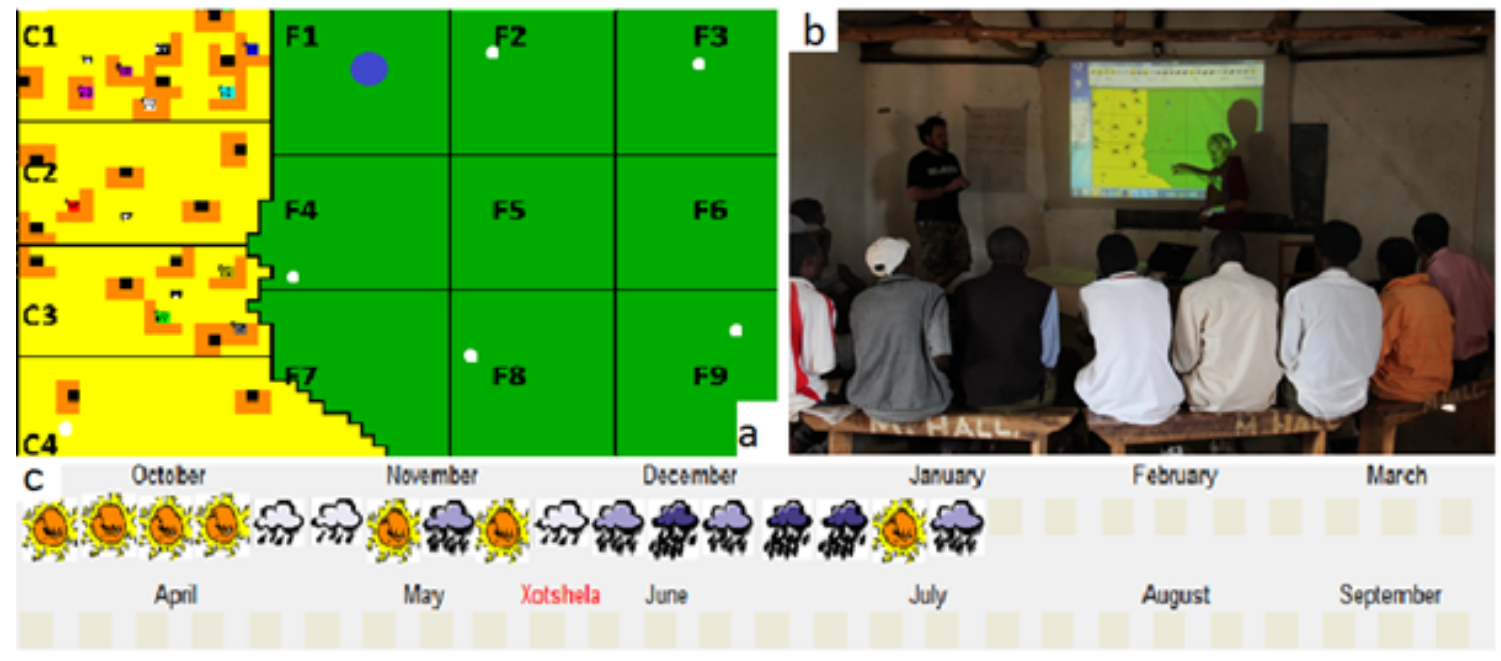

based model, they correspond to units of computer programs. The model supporting the game is run through steps (months). At each step, players will make playing decisions. In their functioning, modules take the current state of the virtual environment and players' actions into account in order to update the virtual environment and characters' status. e.g., a "climate" module controls the rainfall pattern displayed; the "wildlife" module controls the behavior of wildlife in the game; the "cattle" module will update cattle body condition.

- Action: playing decision made by a player, e.g., planting a field; selling a cow; protecting fields from elephants, or negotiating with another player.

\section{KULAYIJANA: CODESIGN OF A ROLE-PLAYING GAME}

\section{Setting up a codesign team}

The codesign team gathered three researchers and ten villagers: nine men and one woman were invited to join the team either because we knew them personally and thought they would provide relevant insights or because the headman, the local representative of traditional authorities, trusted them. Their ages ranged from 39 to 57 years old. All but one were the head of their household. Three were village heads, one was the secretary of a village head, two were involved in dip-tank committees, one was the local chairman of a community project developing goat husbandry, and four held no position at the community level. They originated from the different villages in the study area. Our local translator was also part of the team. Occasionally, external researchers joined the team during workshops, either to observe or participate.

\section{Initiation: a prototype version of the game}

Information gathered during the ethnographical fieldwork was used to design a "prototype version" (V0) of the game. The V0 was computer based and developed using CORMAS, an agentbased simulation platform dedicated to renewable resources management issues developed by the Centre de coopération internationale en recherche agronomique pour le développement (CIRAD) (Le Page et al. 2012). The V0 was brought by the researchers as an entry point to initiate the codesign process. The main challenge was to come up with a game that was realistic enough to legitimize us as facilitators of the modeling process and catch the interest of the future codesign team members by showing the potential outcomes of their participation while at the same time leaving room for the team members to take over the modeling process and suggest improvements. Hence the need to introduce a highly simplified yet realistic model using the ethnographical fieldwork.

The game covered one agricultural year, from the beginning of October one year to the end of September of the next. Each player was in charge of a farm comprising five fields of about 0.5 acres or "umfollow," corresponding to the area that can be plowed in one day (in orange in Fig. 3a ). Each player also owned a single herd of five cows, which corresponds to the average herd size observed. At the beginning of each round (month), players had to make individual decisions concerning (i) which paddock their cattle would use for grazing during the coming month and if they would be accompanied by a herd boy, (ii) their farming decisions (planting, harvesting), and (iii) cattle transactions (sell/buy any cows). 
Following Barnaud's advice (2013), the virtual environment was similar to reality, i.e., it comprised a communal area and a forest, but did not match the study area exactly. This allowed the participants to create a distance from reality and provided a nonthreatening environment whithin which local actors could freely propose ideas without being constrained by the presence of sensitive issues like the right of access to the forest (Fig. 3a).

Moreover, V0 was deliberately incomplete and unrealistic to encourage participants to make propositions and discuss them. The players could only choose between a short-term or a longterm variety from the same crop (respectively 3 or 4 months to produce grains), with no occurrence of failures due to adverse climatic conditions. Predation of cattle by wild carnivores only occurred in the forest and was calculated by a simple probabilistic model. Neither fodder dynamics (depletion or growth) nor cattle body condition (fattening or thinning) nor water pans filling had been included in the prototype version. The 13 paddocks that made up the environment represented grazing units with four levels of forage availability (null, poor, medium, and high), which were updated directly by the facilitator according to the amount of rainfall and grazing pressure. Elephants were not included on purpose. "Forgetting" them was our stratagem to trigger a discussion about wildlife in the game. Finally, daily rainfall records from the 2012-2013 rainy season were used to approximate weekly and monthly rainfall (Fig. 3c). Rainfalls were the only quantitative data-based elements included in the game.

\section{Iterative codesign}

ComMod processes are usually achieved by iterations. Field workshops aim at testing and improving the model. Each workshop provides new elements or modifications that researchers will use to improve the model functionalities. Each set of modifications is tested in the following workshop in order to validate the changes (e.g., Souchère et al. 2010). The first workshop was the moment when the different members of the team met each other around a common objective. Creating an atmosphere of mutual trust was necessary; it was particularly important to create a fair and balanced arena between researchers and nonresearchers. The Magoli community hall was chosen for the venue because the local members of the team could easily come to that place and would feel confident there.

Once the different members of the team had been introduced, we presented the research project and the specific objectives of the codesign process. It was made clear from the beginning that the codesign process was open to suggestions and that each participant could propose new rules during the game. After exposing the principles of the V0 by asking a local member to play a test month, the rest of the first day was spent playing with all the team members (Fig. 3b). A first debriefing was done at the end of the day, during which the team shared impressions about the game and decided on a list of topics to be discussed the following day. The second day of workshop was dedicated to a collective revision of the game. Rules concerning livestock predation by lions were entirely redesigned. Unsurprisingly, elephants were brought in by local members. A simplified elephant crop-raiding module was designed by the team, along with the possibility for players to protect their fields from elephants. The addition of livestock diseases was proposed but finally abandoned. Rules of costs-benefits were also improved, and the cattle selling/purchase rules were formalized. The crop module wasn't satisfying for most members of the team, and was therefore intensively discussed and redesigned. The idea of having only one type of crop was kept, but development stages were added, along with the occurrence of crop failures due to droughts or floods. A new action was added: when harvesting, players would be able to either collect crop residues and feed their cattle later with them, or leave them in the fields where any cattle could eat them. In the V0, rains were displayed at the end of the month. The local members of the team asked for a weather forecast at the beginning of each month, explaining that in real life they had access to short-term weather forecasts, either through newspapers, radios, or traditional weather forecasting methods (Perrotton 2015). Finally, the biggest contribution to the game of this first workshop concerned livestock grazing management. The subdivision of the environment in paddocks was kept, so was the rule that each player could use one paddock per month to graze his cattle. A completely new module of grazing resources dynamics was designed around the notion of carrying capacity. It was decided that the effects of grazing on a paddock would also depend of the land cover, with slightly better pastures in the forest, and on the season. The name "Kulima Kufuma," meaning "farming to get rich" in chiNambya (one of the local languages) was chosen by local members of the team at the end of the first workshop.

Following the first workshop, the V0 was modified into the first codesigned version (V1) incorporating all the team's decisions. Two other workshops held in November 2014 and April 2015 resulted in the production of $\mathrm{V} 2$ and $\mathrm{FV}$, the final version (Fig. 2). During these workshops, the core of the game (e.g., rules, modules) were collectively revised in order to create a more realistic game that could easily be played by any local villager. Some of the final modules were collectively built during workshops, some were designed by researchers and validated by the team. A second climatic year, also relying on meteorological data collected in Hwange National Park (1921-1922) was chosen to represent a drought. It had been one of the "worst" rainy seasons of the last century for agricultural production, with low annual rainfall and several dry spells. A full game session now covered 2 years played in sequence, the "good year" first (20122013), followed by the "bad year" (1921-1922). The codesigners also discussed the physical support for the game. Computer-free (V1) and computer-based (V0, V2, FV) versions of the game were tested. The map was initially projected on a wall (V0), in later versions (V2, FV) it was projected on a table around which all players could move freely, position their pawns and interact with each other or with the game facilitator (Fig. 4).

Additionally, the computer would record every decision taken by each player (e.g., in which paddock the cattle had been put to graze each month, or the type of crops used and the success rate) together with the occurrences of adverse events (e.g., the number of cattle killed by lions and crop raiding by elephants). This information was very useful to foster postplaying discussions.

At the end of the third workshop, the team agreed that the game was ready to be implemented, and five members of the team volunteered to facilitate playing sessions with villagers. 
Fig. 4. The final version of the game. The projector displays the board game on a central table. Players are around the board and signify their actions by moving their pawns. Actions are entered in the computer by the operator sitting at another table (computer screen up front). The "game master"(dressed in a white long-sleeved shirt, to the right) leads the game, the "ank master" (absent in the picture) controls all the transactions, and a third facilitator records minutes (striped t-shirt, at the back).

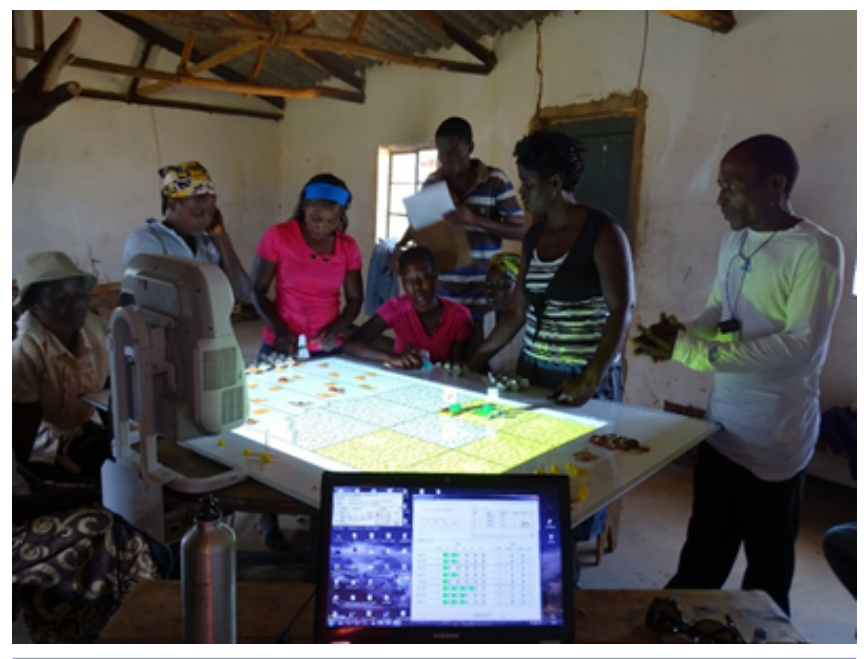

Almost a year after initiating the codesign, the game had been substantially transformed and a new name was proposed by local members of the team: "Kulayijana," meaning "teaching each other" in ChiNambya. A complete description of this final version of the game is provided in Appendix 1.

\section{PERCEPTION OF KULAYIJANA BY THE CODESIGN TEAM}

The 13 members of the codesign team (ten villagers and three researchers) were asked to respond to individual questionnaires between the last workshop and the first playing session with other villagers. We asked the team members to comment about the initialization of the process, the workshops, the final version of the game, and their perception of this participatory process.

\section{A collective effort toward Kulayijana}

All the members of the team acknowledged they had a high degree of freedom to propose original ideas during the codesign of the game, and everyone could recall at least one personal idea that had been kept in the final version of the game. The atmosphere during the workshops was given an average ranking of $8.5 / 10$ $( \pm 1.5)$. As one local member remarked:

\section{It was said to be our game, and we made it like that.}

The first two versions of the game (V0 and V1) were judged too slow by $70 \%$ of the team. The direct use of pawns to signify decisions $(55 \%)$ introduced in the V1 and the choice of a central game board improved the interactions between players for $70 \%$ of the team. Nevertheless, the computer-free V1 made playing too tedious for $69 \%$ of the team members because all updates (including crop stages) had to be done manually. The strengths of the final version cited by the team members were the speeding up of the game $(69 \%)$, its clarity $(42 \%)$, and the fact that the consequences of playing actions could easily be monitored and recorded $(38 \%)$. The whole team declared being satisfied with the final version, although some members suggested possible additional improvements such as the inclusion of seasonal rivers (suggested by three members), or the display of alternative sources of climatic information, such as songs played by birds that "[they] use here to know when it is about to bring rain, they are our reporters." This last suggestion echoes previous research (Perrotton et al., unpublished manuscript). The three researchers of the codesign team also agreed that the speed of forage depletion/(re)growth according to stocking densities and the variable describing cattle body condition (thin/medium or fat) could be improved. However, the spatial dimensions of the environment in the game were not defined accurately and not deemed essential by the codesign team, and refining the model would necessitate costly on-site experiments with exclosures and controlled grazing densities.

\section{Self-empowerment and appropriation}

When asked about their motivation in joining the process, six local members answered that it was curiosity and the desire to learn, three answered that they wanted to share ideas, and one wanted to help researchers that he knew personally. The analysis of questionnaires highlights the appropriation of the game by local team members. An open question asked codesigners to give one or more potential uses of the game they had created. As shown in Fig. 5, most of the respondents emphasized the reflexive dimension of "Kulayijana." This directly echoes our initial objective to empower rural communities. Indeed, two researchers and six local members saw the game as a way for communities to reflect about their own practices and discuss them among themselves. Two local members explained that the game should be used in schools "So that children grow up with a better understanding of cattle herding." The second group of potential uses is also consistent with our original objectives as they are related to the potential use of the game as a research tool through which researchers could collect data and better understand local practices and cattle herding. One of the researchers suggested the game could serve to strengthen working relationships between local actors. Finally, two unexpected uses were proposed by local members: alleviate poverty and educate communities about climate change. Although only mentioned by two people, this emergence of endogenous perspectives for the game is a first indication of an ongoing appropriation.

Bonds were created between local members and researchers, and the resolve to continue working to improve the game or design other games was expressed by $70 \%$ of the team. Two potential topics for future games emerged from the questionnaires. Three local members proposed focusing on interactions with wildlife, particularly crop raiding and predation, but also conservation to "try to find solutions." Two other local members expressed a real concern about the loss of trees in the communal land and thought that a game focusing on tree management could address the matter. Through the construction of the game and its implementation, the game was perceived as a self-learning and self-empowering tool.

A final indication of appropriation is the spontaneous desire to facilitate playing sessions of five members of the team. Among 
Fig. 5. Potential future uses of the game as perceived by the team members. The different potential uses of the game were given by local members (green, $n=10$ ) and researchers (red, $n=3$ ) in the questionnaire survey administered before the playing sessions (May 2015).

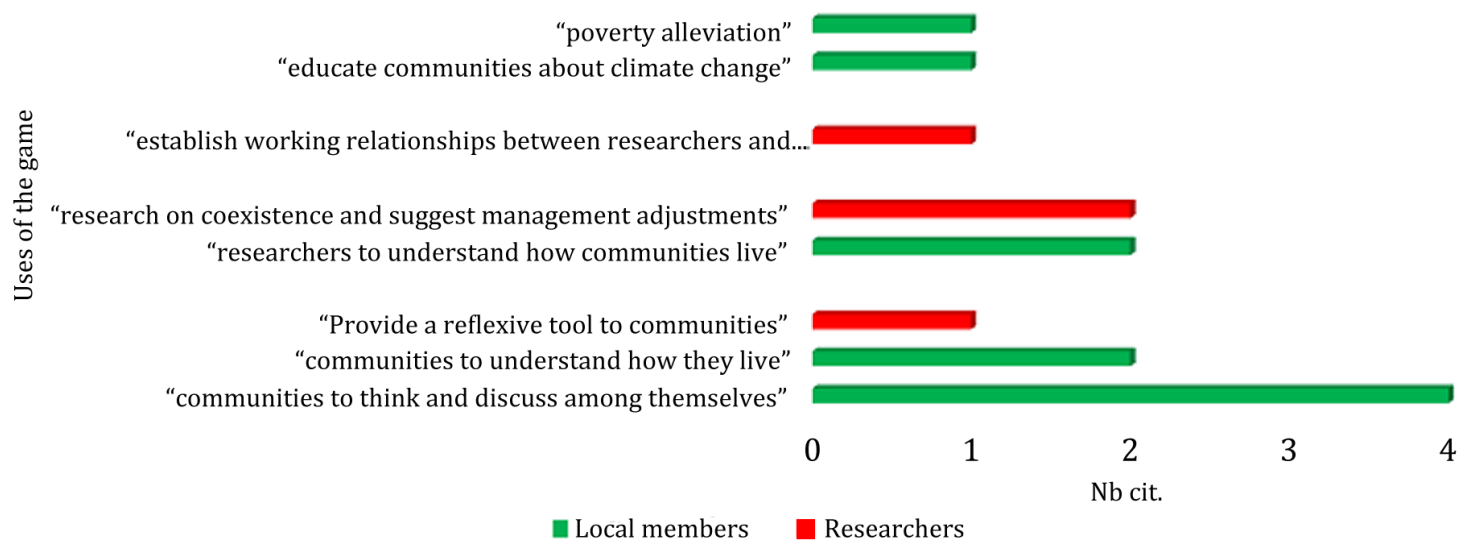

the motivations to volunteer playing sessions, one emphasized the educational dimension of the game and said that he wanted to "help [his] community to improve the way people drive their cattle," whereas another one saw it as training to "be a leader." Three said that they were proud of the game and wanted to elicit other villagers' opinions of it.

\section{VALIDATION OF THE GAME BY FARMERS}

A model is always seen by those who designed it with indulgent eyes because of an inherent sense of ownership. "Kulayijana" was designed to be played by multiple stakeholders. To ensure it would make sense for all of them, we first organized a playing session with naive villagers, i.e., who were not part of the codesign team. "Kulayijana" requires a minimum of four facilitators. The "game master" is in charge of the facilitation in the strict sense. The "bank master" is in charge of controlling and collecting all transactions during the game. A computer operator enters players' decisions in the computer and ensures the smooth running of the model supporting the game. Finally, in order to stimulate the general discussions after the playing session, minutes are recorded by the last facilitator. The facilitation by local members allowed us to hold playing sessions in local languages. An introductory speech for the game was collectively written in local languages, and a blank game was played as training game with workers from a neighboring hotel as players.

Three playing sessions were organized (Fig. 2), and a total of 22 villagers played "Kulayijana." The villagers (hereafter referred to as "players") were chosen by the facilitators and the researchers, covering the different villages of our study area. Players were neighbors or friends and, except for two players, direct family links were avoided. Two dimensions of the game were assessed through general discussions and individual questionnaires administered after the game: the appreciation of the game by local villagers and the consistency of played strategies with strategies observed in real life.

\section{Players' appreciation of the game}

The game was judged "very easy to play" by $18 \%$ of the players, "easy" by $25 \%$ of the players, "not so easy" by $46 \%$ of the players, and "not easy at all" by $11 \%$ of them. When asked to summarize "Kulayijana" in up to three words, the 22 players mostly used "real" $(22.7 \%)$, followed by "learning" $(18.2 \%)$ and "teaching" (18.2\%). Other words like "game for adults," "life," and "mind opener" were also used to describe a playing experience that was closer to training than playing. As expressed by a player:

\section{It's not a game, it's [our] real life.}

All the players thought playing "Kulayijana" was useful $(75 \%)$ or very useful $(25 \%)$ and served as an opportunity to think (40\%), learn $(28 \%)$, open their perspectives $(12 \%)$, test agricultural practices $(8 \%)$, or train $(8 \%)$. The self-learning dimension highlighted by codesigners was therefore confirmed by players.

Players were asked if the game was "very realistic," "realistic," "not too realistic," or "not realistic at all." Although they mentioned some differences with reality, none of the players answered negatively to the question, $57 \%$ of the participants found the game "very realistic," and $43 \%$ found it "realistic". Opinions about possible differences between the game's modules and reality varied between the modules. Unsurprisingly, the climate module (based on empirical data) was realistic or very realistic for $93 \%$ of the players. Eighty-two percent of the players validated the crops dynamics module, although two thought the game was missing crop-raiding birds such as the queleas (Quelea quelea). Among the $18 \%$ of players who noted some differences, three explained that crops do not grow the same everywhere so that the game should include different types of soil, and four thought that crops were ripening faster in the game than in real life. For $85 \%$ of players, wildlife in the game presented no difference at all or slight differences with reality. The confinement of lions to the forest was criticized by $18 \%$ of the players who acknowledged occasional attacks within the communal area. Three players $(13 \%)$ answered that elephants would enter the 
communal land more often in reality, but that they would cause less damage than in the game. Although validated by $68 \%$ of the players, the livestock module received more skeptical opinions from the players, with $32 \%$ of them mentioning real differences between their gaming experience and reality. Some of them explained that the difference of pasture availability between the communal land and the forest was underestimated in the game $(16 \%)$, others mentioned that livestock body condition was decreasing too fast in the game $(26.3 \%)$, or that on the contrary livestock were staying "fat" longer in the game compared with their experience in real life $(26.3 \%)$. Finally, $17 \%$ of the players suggested that unlike in the game, not all farmers own cattle and that this inequality generated social interactions (lending, fostering, and bartering) missing from the playing sessions.

\section{Strategies in the game vs. strategies in real life}

It is always challenging to assess the degree to which decisions made by players during gaming sessions are related to their actual practices. Out of the 22 players, 61\% acknowledge having reproduced their farming and cattle herding strategies "exactly" in the game and $35 \%$ declared that their playing strategies were "almost" like their real-life strategies. For $66 \%$ of the players, these differences were said to be due to the discovering of the game. Only $4 \%$ of players answered that their playing strategies were "not really" similar to their actual practices.

The general pattern of cattle-herding strategies as identified and described in the ethnography was reproduced by players, confirming our field observations. In particular, if the choice of a date for "xotshela" (release) never appeared explicitly during playing sessions, the "habit" of favoring the forest during the cropping season and waiting for harvests to be finished to release them in the village was globally reproduced and respected. These patterns were confirmed by an independent study of cattle movement using GPS collars deployed in the study area (Fig. 6).

\section{KULAYIJANA AND PROTECTED AREAS MANAGERS}

To test how the game would be perceived by the other types of stakeholders who were not involved in its design, a quick presentation of the game was given to protected areas managers in February 2016. The managers of each protected area were then invited to appoint three members of their staff to join them and participate in a playing session held at the headquarters of Hwange National Park a few days later. Seven players joined this playing session, four officers from Hwange National Parks and three from the Sikumi Forest (including the area manager). The session was facilitated by three local members and a researcher as computer operator.

The fact that local members of the codesign team agreed to facilitate such a session at the Hwange National Park headquarters is encouraging for the next steps in our work. As one of them declared on the way:

It's our game, we are proud of what we have done. It shows our life, what we need, and what we have to live with [wildlife]. I hope they will like the game and see ways we can play together.
Fig. 6. Use of communal lands and forest estimated using quantitative outputs from playing sessions and independent cattle GPS data. The graphs represent the percentage of time spent by cattle in the communal land (Village) and in the protected area (Forest) for each season. Rainy season = October to May; Cold Dry season= June to July; Hot Dry season = August to September. Left: Estimates from the game were obtained by pooling monthly grazing decisions of 22 players during three playing sessions. Right: Real time spent by cattle was obtained from nine cattle equipped with GPS collars between 2012 and 2014 (Valls-Fox 2015).
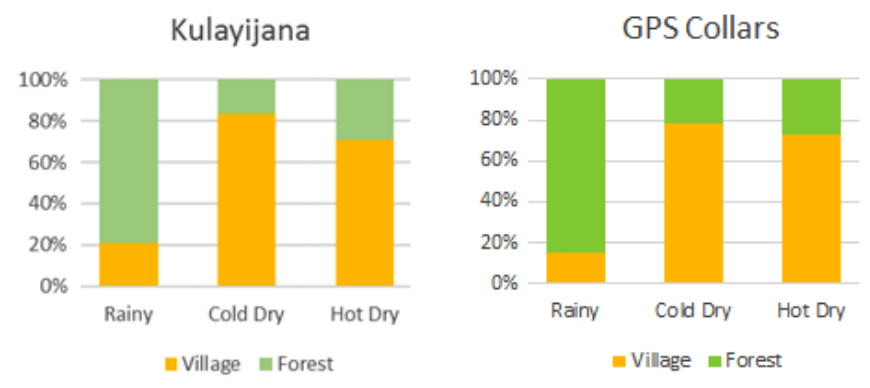

Indeed, villagers were proud of a game they had developed and mastered. During the game, facilitated in English, a very respectful atmosphere was created. Parks and Forestry managers appreciated the game. Below are a few quotes gathered during the session:

I'm failing with my fields because of these elephants (NParks officer).

I need to go in the forest with my cows but I'm afraid of lions (NParks officer).

I'm harvesting as soon as I can, elephants will come again (Forestry officer).

I don't want to keep cattle, I'd rather sell them and have money (NParks officer).

As always, a general discussion followed the game during which strategies adopted by the players were analyzed. The local members of the team compared their experience of the game, i.e., what their fellow villagers had done, and the way protected areas managers had played. The latter had chosen a radically different strategy: buy thin cattle, fatten them during the rainy season and sell them before they lost weight during the dry season. Although this strategy made them "rich," local facilitators commented by saying that real villagers wouldn't do that because cattle were at the heart of their culture and a sign of social and economic wealth that money could not replace. This was the first confrontation of the different mind-frames of local actors. When asked about their perspectives on this game, two different attitudes were observed. National Parks officers remained relatively quiet, which we explain by the considerable top-down pressure they currently experience due to an increase in big-game illegal hunting and scandals. Managers of the Sikumi Forest on the other hand were very enthusiastic: 


\begin{abstract}
This game is great, it could be useful for me to understand better the way they [the villagers] use my forest, and if we could play together and discuss, we could produce good management plans. (Forestry officer)
\end{abstract}

This last statement bodes well for the coming steps in the creation of a multistakeholder arena, at least at the local level. The foundations of a locally designed multistakeholder arena are in place. The potential use of "Kulayijana" was acknowledged by local actors willing to continue the process, and the marginalized actors legitimized in the eyes of at least one protected area managing team.

\section{DISCUSSION}

The initial objective of the project was to initiate a process aimed at setting-up a fair arena for negotiations between multiple stakeholders regarding the management of protected areas and their peripheries. First, we involved the most marginalized actors (local farmers) in the codesign of a computer-based role-playing game focusing on their own activities, hoping that it would empower them and therefore contribute to righting the power imbalances that often hinder multistakeholder collaboration (Beymer-Farris et al. 2012). Although only a single type of actor was involved, we faced several challenges. In this discussion, we draw lessons from our experience and return to issues of legitimacy and uncertainties. We also discuss the challenge of codesigning an interactive role-playing game that would make sense to people who have not participated in its creation, and that would attract them to engage in a multistakeholder dialogue supported by this tool. This leads us to the current limitations of our work, and to the necessary next steps toward the multistakeholder arena.

\section{Power balance and legitimacies: a strategic posture}

Social and political equity are inherent objectives of participatory approaches (Cornwall and Gaventa 2001). As highlighted by Barnaud and van Paassen (2013), participation often takes place in heterogeneous social contexts characterized by conflicts of interests and power asymmetries. This raises questions about the legitimacy of external agents (e.g., the researchers) to conduct participatory processes. According to the authors, ignoring the complexity of the social context and particularly power asymmetries might actually give more influence on the outcome of the participatory process to powerful stakeholders than to marginalized ones, therefore reinforcing initial asymmetries. The dilemma of participation stems from the fact that designers of a participatory approach cannot claim neutrality without being accused of being manipulated by the most powerful actors, whereas on the other hand, their legitimacy to endorse a nonneutral posture empowering particular stakeholders is often questionable. Managing this dilemma requires a posture more than a method. The "critical companion" posture suggested by Barnaud and van Paassen (2013:2) is a "non-neutral posture that recognizes the necessity to take into account power asymmetries to avoid the risk of increasing them." In the introduction and in the description of our study area, we highlighted historical asymmetries between rural communities and conservation agencies. Although Zimbabwe pioneered the formalization of community-based natural resources management with the iconic CAMPFIRE program launched in the early 1980s (Murphree 2013), conservation management remains the prerogative of state institutions, and rural communities are effectively not recognized as legitimate actors in the matter. Designers of participatory processes should, therefore, ensure that the less influential stakeholders are given a voice and are able to assert their interests. This implies that all actors should not be involved equally in all the stages of a multistakeholder process, at least not until the less powerful are able to defend their interests (Edmunds and Wollenberg 2001). Codesigning the tool intended to support a dialogue arena was a way to empower rural communities. One could argue that we did not empower rural communities as a whole, but only a few individuals who were involved in the codesign activities, and among them, five facilitators in particular. Nevertheless, we provided evidence that "Kulayijana" represents rural communities' perspectives of the interaction between communal land and wildlife. As such, we made sure that other actors playing the game would be exposed to villagers' interests, whether villagers are present during the playing session or not. Furthermore, the sense of ownership of the game by the codesign team and their desire to use the game in multistakeholder negotiations are encouraging.

When involved in a participatory process, researchers need to be reflexive about their posture and about their social position in the system they work in (Daré et al. 2010). The same way we considered power asymmetries and adopted a strategic posture, we also considered how local actors perceived us. Many conservation-related research activities are conducted in the area in collaboration with Hwange National Park and the Sikumi Forest authorities (e.g., Chamaillé-Jammes et al. 2008, Muboko et al. 2014, Ndaimani et al. 2016). This often leads rural communities to assimilate all researchers as conservation agents. We first had to change this perception and gain legitimacy in the local villagers' eyes. The ethnographic field work undertaken beforehand and the months spent living in the villages were necessary to gain this legitimacy. As stated by Mathevet et al. (2011), the engagement of local actors as effective collaborative partners within the working team is key. Building legitimacy is an iterative and adaptive process engaged between actors (Barnaud 2013). The positive perception of the codesign process by local team members, the sense of ownership of the model that grew progressively, and their expressed motivation to pursue the collaboration are significant signs of an acquired legitimacy that needs to be nurtured during the next steps of our work.

\section{Modeling with nonacademics: simply prepare complexity}

Unlike other participatory modeling processes based on roleplaying games (e.g., Souchère et al. 2010, Gourmelon et al. 2013), we chose not to start by codesigning a conceptual model, but to initiate the participatory modeling process with an object that already took the form of a role-playing game. This strategy relied on the idea that a role-playing game, that is a form of interactive model, is easy for nonacademics to understand, analyze, and criticize. Participants are comfortable providing direct inputs when put in an active position where each action is consequential and shows the strengths or the weaknesses of the underlying model. Yet, codesigning a model with people that are not used to manipulating such abstract and stylized representations proved to be challenging.

Social-ecological dynamics are complex and unpredictable (Epstein et al. 2013), and modeling any social-ecological system 
implies dealing with uncertainty (Walker et al. 2003, Brugnach et al. 2008). The appropriate level of details needed to describe a specific system adequately to design a model is an ongoing debate in the scientific community (Evans et al. 2013). Simple models will deliver insights on general patterns (Parker et al. 2003) but will fail to accurately describe specific systems. Complex models relying on empirical data may represent "real-world" contextspecific problems more accurately, but their high level of detail requires a large amount of data and makes them difficult to use with nonmodelers, and their outputs can seldom be generalized to other situations (Sun et al. 2016). In choosing the right degree of model complexity, the critical point remains the goal assigned to the process of designing and/or using them. Assuming that simple abstract models are mostly useful for theory building and education whereas more complex empirically grounded models are meant for prediction and decision-making support, Sun and colleagues (2016) argue that models mixing simplified and empirical components could lead to greater confusion. With our specific objective to support the setting-up of a multistakeholder dialogue arena by first involving grassroots people (smallholder farmers), we relied on empirically grounded stylized facts to design the prototype version (V0) of the game. It allows an easier understanding of the design's objectives by local members, while leaving space for a collective complexification on the model. In an iterative process like ours, the choice of which elements are included or left out of the first version is critical. These elements must reflect a sound initial knowledge of the system, without constraining too much the codesign process. The V0 of our roleplaying game was also purposively incomplete as we left out several elements of the social-ecological system studied, although we suspected that they would play an important role. This eased the initiation of a critique/redesign dynamic from local members. In a way, we distorted the KISS ("keep it simple stupid"; Axelrod 1997) principle: the extreme simplification did not seek to enable producing generic results but to stimulate the involvement of local actors in the model codesign process. Initiating the codesign with an incomplete and partly discordant representation of reality also helped highlight the need for local actors to identify and fill the knowledge gaps, therefore breaking the "foreigner white-male positionality of researchers" (Stringer et al. 2006). During the design of Kulayijana, the complexity of the game increases gradually through collective negotiation: existing modules were refined, and/or new modules were included whenever the participants deemed it necessary.

\section{Strategic negotiation of uncertainties}

Uncertainties are at the core of social-ecological systems (Walker et al. 2003, Mathevet et al. 2016). Epistemic uncertainties come from the lack of knowledge about a given system (we do not know everything). Ontological uncertainties are related to the intrinsic unpredictability of social-ecological systems (our scientific understanding does not allow us to predict all of the dynamics and properties) (Walker et al. 2003). When looking at the interactions between actors of a social-ecological system, a third type of uncertainty appears: different actors have different views and opinions of a given reality, therefore voicing different yet valid interpretations of reality (Dewulf et al. 2005, Brugnach et al. 2008). Uncertainties have become highly topical to natural resources management and environmental science (Pahl-Wostl 2007, Brugnach et al. 2008). Over the past decades, the perception of uncertainty by researchers has changed. Uncertainty is no longer something to get rid of, but is accepted as an inherent and necessary part of life (Brugnach et al. 2008). Approaches to deal with and model uncertainties have been developed, most of the time relying on formal and quantitative methods using statistical analyses (e.g., with confidence intervals, probability distributions). When applied to epistemic or ontological uncertainties, such approaches can provide useful results, for instance probabilistic estimates of flood events (Chen and $\mathrm{Yu}$ 2007) or probabilistic climate forecasts (Gneiting et al. 2007). Nevertheless, when uncertainty arises not only from a lack of knowledge, but also from the fact that the problem cannot be clearly defined, that information is incomplete and not quantifiable, and that different legitimate views of the system exist - in other words, when we deal with-wicked" problems - a probabilistic transformation of uncertainty is impossible (Allen et al. 2011).

To cope with uncertainties, we chose the negotiation approach (Leeuwis 2000). Our vision of the system, that is our mind-frame, necessarily differed from that of local actors. The ethnographical fieldwork contributed to acquiring a partial understanding of endogenous mind-frames, but a deeper understanding of local mind-frames was necessary. An exogenous role-playing game would have been a manifestation of the researcher's mind-frame, and using it with people having different mind-frames may increase rather than reduce and hinder its use in a multistakeholder arena. Through the codesign process, we went from a high level of ambiguity of multiple mind-frames analyzing reality differently, to a collectively negotiated consensual mindframe shared by researchers and local actors.

During the codesign, each actor brought in his own knowledge, and mixed and negotiated it with the others. In other words, actors were negotiating uncertainties. For instance, researchers did not know the specific composition of the grazing lands used (epistemic uncertainties) or the impact of cattle grazing on fodder availability in the study area (ontological uncertainties). To cope with the lack of scientific knowledge, we collectively designed a forage module for the game based on the combined experiential knowledge of researchers and local members of the team who are custodians of the system. As the exact dietary regime of cattle is complex, multifactorial (e.g., age, diseases, physiological and reproductive status...) and adaptive in space and time, we proceeded in a similar way to negotiate the module describing the dynamics of cattle body condition. Codesigning the game was therefore a way to collectively negotiate a consensual uncertainty.

\section{CONCLUSION}

Addressing the issue of coexistence between a protected area and its rural periphery, we engaged in a long-term participatory process to establish a multistakeholder arena. Our hope was to facilitate fair and efficient discussions and negotiations between local actors to produce socially and ecologically sustainable management practices. In this paper, we present the first step that consisted of the codesign of a role-playing game for local farmers. "Kulayijana" was validated by other members of local communities who perceived the game as a fair representation of their reality, allowing them to reproduce their actual practices and improve their own understanding of the social-ecological system. The game was also praised by Sikumi Forest managers as a promising tool to establish a dialogue with the farmers, which was our main objective for this phase of the project. 
One of the current limitations of "Kulayijana" is that it only represents one type of actors (rural communities), whereas the ambition is to promote multistakeholder interactions. In order to promote the dialogue, involving other local actors appears as the necessary next step. This involvement could take different forms, and must be decided collectively with the codesign team and protected areas managers. A possibility would be to include local actors in the identification of scenarios and social-ecological indicators that could be tested and explored with "Kulayijana." Such an endeavor could lead to additional refinements and modifications of the current game. Another option would be to formalize strategies played in the different sessions to define the behavior of agents in autonomous simulations. Collectively designed scenarios could therefore also be tested through agentbased simulations.

The enthusiasm of local actors must not make us forget that the top-down centralized management of Zimbabwean protected areas remains. If we aim to foster the creation of participatory management plans involving conservation and rural actors, a local initiative is insufficient, and higher hierarchical levels will have to be convinced. This next step will be crucial to the success of our endeavor. This is why national workshops and meetings are already organized and will involve regional and national actors of conservation in Zimbabwe.

Responses to this article can be read online at: http://www.ecologyandsociety.org/issues/responses. $\mathrm{php} / 8962$

\section{Acknowledgments:}

The authors would like to thank the 10 localmembers of the codesign team who made this work possible. We would like to thank also Bernard Triomphe and Christine Raimond for their advice on conducting workshops, and the members of the Lysode consultancy cooperative and the ComMod network for their expertise and help. We would like to particularly thank the family who hosted us for several weeks in Magoli and our two translators whose help was crucial and often enlightening. This work was conducted within the framework of the Research Platform "Production and Conservation in Partnership" ( RP-PCP) and funded by a grant from the French National Agency for Research (ANR/CEPS 2011, projet SAVARID).

\section{LITERATURE CITED}

Agrawal, A., and Ostrom, E. 2001. Collective action, property rights and decentralisation in resource use in India and Nepal. Politics and Society 29(4):485-514. http://dx.doi.org/https://doi. org/10.1177/0032329201029004002

Allen, C. R., J. J. Fontaine, K. L. Pope, and A. S. Garmestani. 2011. Adaptive management for a turbulent future. Journal of Environmental Management 92(5):1339-1345. http://dx.doi. org/10.1016/j.jenvman.2010.11.019

Allen, C. R., and A. S. Garmestani. 2015. Adaptive management. Pages 1-10 in C. R. Allen and A. S. Garmestani, editors. Adaptive management of social-ecological systems. Springer, The Netherlands. http://dx.doi.org/10.1007/978-94-017-9682-8_1
Allen, C. R., and L. H. Gunderson. 2011. Pathology and failure in the design and implementation of adaptive management. Journal of Environmental Management 92(5):1379-1384. http:// dx.doi.org/10.1016/j.jenvman.2010.10.063

Andersson, J. A., M. de Garine-Wichatitsky, D. H. M. Cumming, V. Dzingirai, and K. E. Giller. 2013a. People at wildlife frontiers in southern Africa. Pages 1-11 in J. A. Andersson, M. de GarineWichatitsky, D. H. M. Cumming, V. Dzingirai, and K. E. Giller, editors. Transfrontier conservation area: people living on the edge. Earthscan, Routledge, London, UK; New York, New York, USA.

Andersson, J. A., V. Dzingirai, and D. H. Cumming. $2013 b$. TFCAs and the invisible peoples. Pages 12-24 in J. A. Andersson, M. de Garine-Wichatitsky, D. H. M. Cumming, V. Dzingirai, and K. E. Giller, editors. Transfrontier conservation area: people living on the edge. Earthscan, Routledge, London, UK; New York, New York, USA.

Ansell, C., and A. Gash. 2008. Collaborative governance in theory and practice. Journal of Public Administration Research and Theory 18(4):543-571. http://dx.doi.org/10.1093/jopart/mum032

Axelrod, R. M. 1997. The complexity of cooperation: agent-based models of competition and collaboration. Princeton University Press, Princeton, New Jersey, USA. http://dx.doi. org/10.1515/9781400822300

Balint, P. J., editor. 2011. Wicked environmental problems: managing uncertainty and conflict. Island Press, Washington, D. C., USA. http://dx.doi.org/10.5822/978-1-61091-047-7

Barnaud, C. 2013. La participation, une légitimité en question. Natures Sciences Sociétés 21(1):24-34. http://dx.doi.org/10.1051/ $\underline{\mathrm{nss} / 2013062}$

Barnaud, C., C. Le Page, P. Dumrongrojwatthana, and G. Trébuil. 2013. Spatial representations are not neutral: lessons from a participatory agent-based modelling process in a land-use conflict. Environmental Modelling and Software 45:150-159. http://dx.doi.org/10.1016/j.envsoft.2011.11.016

Barnaud, C., P. Promburom, T. R. Gurung, C. Le Page, and G. Trébuil. 2006. Companion modelling for collective learning and action in water management: lessons learnt from three case studies in northern Thailand and Bhutan. International symposium towards sustainable livelihoods and ecosystems in mountainous regions, Chiang Mai, Thailand.

Barnaud, C., G. Trébuil, P. Dumrongrojwatthana, and J. Marie. 2008. Area study prior to companion modelling to integrate multiple interests in upper watershed management of Northern Thailand. Japanese Journal of Southeast Asian Studies 45(4):559 585 .

Barnaud, C., and A. van Paassen. 2013. Equity, power games an legitimacy: dilemmas of participatory natural resource managment. Ecology and Society 18(2):21. http://dx.doi. org/10.5751/es-05459-180221

Beymer-Farris, B., T. J. Basset, and I. Bryceson. 2012. Promises and pitfalls of adaptive management in resilience thinking: the lens of political ecology. Page 283-299 in T. Plieninger and C. Bieling, editors. Resilience and the cultural landscape: understanding and managing change in human-shaped 
environments. Cambridge University Press, New York, New York, USA. http://dx.doi.org/10.1017/cbo9781139107778.020

Bousquet, F., O. Barreteau, C. Le Page, C. Mullon, and J. Weber. 1999. An environmental modelling approach. The use of multiagent simulations. Pages 113-122 in F. Blasco and A. Weill, editors. Advances in environmental and ecological modelling. Elsevier, Paris, France.

Brockington, D., and D. Wilkie. 2015. Protected areas and poverty. Philosophical Transactions of the Royal Society, B 370 (1681):20140271. http://dx.doi.org/10.1098/rstb.2014.0271

Brugnach, M., A. Dewulf, C. Pahl-Wostl, and T. Taillieu. 2008. Toward a relational concept of uncertainty: about knowing too little, knowing too differently, and accepting not to know. Ecology and Society 13(2):30. http://dx.doi.org/10.5751/es-02616-130230

Chamaillé-Jammes, S., H. Fritz, M. Valeix, F. Murindagomo, and J. Clobert. 2008. Resource variability, aggregation and direct density dependence in an open context: the local regulation of an African elephant population. Journal of Animal Ecology 77 (1):135-144. http://dx.doi.org/10.1111/j.1365-2656.2007.01307. $\underline{\mathrm{x}}$

Chen, S.-T., and P.-S. Yu. 2007. Real-time probabilistic forecasting of flood stages. Journal of Hydrology 340(1-2):63-77. http://dx. doi.org/10.1016/j.jhydrol.2007.04.008

Chitakira, M., E. Torquebiau, W. Fergusson, and K. Mearns. 2015. Suggesting an interdisciplinary framework for the management of integrated production and conservation landscapes in a transfrontier conservation area in southern Africa. Pages 265-278 in N. Benkeblia, editor. Agroecology, ecosystems and sustainability. CRC Press (Taylor and Francis Group), New York, New York, USA. http://dx.doi.org/10.1201/b17775-14

Cinner, J. E., T. M. Daw, T. R. McClanahan, N. Muthiga, C. Abunge, S. Hamed, B. Mwaka, A. Rabearisoa, A. Wamukota, E. Fisher, and N. Jiddawi. 2012. Transitions toward co-management: the process of marine resource management devolution in three east African countries. Global Environmental Change 22(3):651658. http://dx.doi.org/10.1016/j.gloenvcha.2012.03.002

Constant, N. L., S. Bell, and R. A. Hill. 2015. The impacts, characterisation and management of human-leopard conflict in a multi-use land system in South Africa. Biodiversity and Conservation 24(12):1-23. http://dx.doi.org/10.1007/s10531-015-0989-2

Cornwall, A., and J. Gaventa. 2001. Bridging the gap: citizenship, participation and accountability. Participatory Learning and Action Notes 40(2001):32-35.

Crane, W., T. Sandwith, E. McGregor, and A. Younge. 2009. Where conservation and community coincide: a human rights approach to conservation and development in the Cape Floristic Region, South Africa. Pages 141-162 in J. Campese, T. Sunderland, T. Greiber, and G. Oviedo, editors. Rights-based approaches: exploring issues and opportunities for conservation. Center for International Forestry Research (CIFOR) and International Union for the Conservation of Nature (IUCN), Bogor, Indonesia.

Cumming, D. H., J. A. Andersson, M. de Garine-Wichatitsky, V. Dzingirai, and K. E. Giller. 2013. Whither TFCAs and people on the edge in southern Africa? Pages 193-203 in J. A. Andersson, M. de Garine-Wichatitsky, D. H. M. Cumming, V. Dzingirai, and K. E. Giller, editors. Transfrontier conservation area: people living on the edge. Earthscan, Routledge, London, UK; New York, New York, USA.

Curtin, C. G. 2014. Resilience design: toward a synthesis of cognition, learning, and collaboration for adaptive problem solving in conservation and natural resource stewardship. Ecology and Society 19(2):15. http://dx.doi.org/10.5751/es-06247-190215

Daré, W., C. Barnaud, P. d'Aquino, M. Étienne, C. Fourage, and V. Souchère. 2010. La posture du commodien: un savoir être, des savoir-faire. Pages 45-67 in M. Étienne, editor. La modélisation d'accompagnement: une démarche en appui au développement durable. Quae Éditions, Paris, France.

d'Aquino, P., and A. Bah. 2014. Multi-level participatory design of land use policies in African drylands: a method to embed adaptability skills of drylands societies in a policy framework. Journal of Environmental Management 132:207-219. http://dx. doi.org/10.1016/j.jenvman.2013.11.011

d'Aquino, P., C. Le Page, F. Bousquet, and A. Bah. 2003. Using self-designed role-playing games and a multi-agent system to empower a local decision-making process for land use managment: the selfcormas experiment. Journal of Artificial Societies and Social Simulation 6(3):5. [online] URL: http://jasss. soc.surrey.ac.uk/6/3/5.html

Dewulf, A., M. Craps, R. Bouwen, T. Taillieu, and C. Pahl-Wostl. 2005. Integrated management of natural resources: dealing with ambiguous issues, multiple actors and diverging frames. Water Science and Technology 52(6):115-124.

Dickman, A. J., L. Hazzah, C. Carbone, and S. M. Durant. 2014. Carnivores, culture and "contagious conflict": multiple factors influence perceived problems with carnivores in Tanzania's Ruaha landscape. Biological Conservation 178:19-27. http://dx.doi. org/10.1016/j.biocon.2014.07.011

Dublin, H. T., and R. E. Hoare. 2004. Searching for solutions: the evolution of an integrated approach to understanding and mitigating human-elephant conflict in Africa. Human Dimensions of Wildlife 9(4):271-278. http://dx.doi. org/10.1080/10871200490505701

Duffy, R. 2000. Killing for conservation, wildlife policy in Zimbabwe. Weaver Press, James Currey and Indiana University Press, Harare, Zimbabwe; Oxford, UK; Bloomington, Indiana, USA.

Duffy, R. 2014. Waging a war to save biodiversity: the rise of militarized conservation. International Affairs 90(4):819-834. http://dx.doi.org/10.1111/1468-2346.12142

Edmunds, D., and E. Wollenberg. 2001. A strategic approach to multistakeholder negotiations. Development and change 32:231253. http://dx.doi.org/10.1111/1467-7660.00204

Epstein, G., J. M. Vogt, S. K. Mincey, M. Cox, and B. Fischer. 2013. Missing ecology: integrating ecological perspectives with the social-ecological system framework. International Journal of the Commons 7(2):432-453. http://dx.doi.org/10.18352/ijc.371 
Étienne, M., editor. 2014. Companion modelling: a participatory approach to support sustainable development. Springer, Dordrecht, The Netherlands; Quae, Versailles, France. http://dx.doi. org/10.1007/978-94-017-8557-0

Evans, M. R., V. Grimm, K. Johst, T. Knuuttila, R. de Langhe, C. M. Lessells, M. Merz, M. A. O’Malley, S. H. Orzack, M. Weisberg, D. J. Wilkinson, O. Wolkenhauer, and T. G. Benton. 2013. Do simple models lead to generality in ecology? Trends in Ecology and Evolution 28(10):578-583.

Fabricius, C., and B. Currie. 2015. Adaptive co-management. Pages 147-179in C. R. Allen and A. S. Garmestani, editors. Adaptive management of social-ecological systems. Springer, Dordrecht, The Netherlands. http://dx.doi.org/10.1007/978-94-$\underline{017-9682-8 \quad 9}$

Funtowicz, S. O., and J. R. Ravetz. 1993. The emergence of postnormal science. Pages 85-123in R. V. Schomberg, editor.Science, politics and morality. Springer, Dordrecht, The Netherlands. http://dx.doi.org/10.1007/978-94-015-8143-1 6

Funtowicz, S., and J. R. Ravetz. 2003. Post-normal science. In International Society for Ecological Economics. Internet Encyclopaedia of Ecological Economics. International Society for Ecological Economics, Washington, D.C., USA. [online] URL: http://leopold.asu.edu/sustainability/sites/default/files/Norton, $\%$ 20Post $\% 20$ Normal $\% 20$ Science, $\% 20$ Funtowicz 1.pdf.

de Garine-Wichatitsky, M., E. Miguel, B. Mukamuri, E. GarineWichatitsky, J. Wencelius, D. M. Pfukenyi, and A. Caron. 2013. Coexisting with wildlife in transfrontier conservation areas in Zimbabwe: Cattle owners' awareness of disease risks and perceptions of the role played by wildlife. Comparative Immunology, Microbiology and Infectious Diseases 36(3):321-332. http://dx.doi.org/10.1016/j.cimid.2012.10.007

Gneiting, T., F. Balabdaoui, and A. E. Raftery. 2007. Probabilistic forecasts, calibration and sharpness. Journal of the Royal Statistical Society: Series B (Statistical Methodology) 69(2):243268. http://dx.doi.org/10.1111/j.1467-9868.2007.00587.x

Gourmelon, F., F. Chlous-Ducharme, C. Kerbiriou, M. Rouan, and F. Bioret. 2013. Role-playing game developed from a modelling process: a relevant participatory tool for sustainable development? A co-construction experiment in an insular biosphere reserve. Land Use Policy 32:96-107. http://dx.doi. org/10.1016/j.landusepol.2012.10.015

Guerbois, C., E. Chapanda, and H. Fritz. 2012. Combining multiscale socio-ecological approaches to understand the susceptibility of subsistence farmers to elephant crop raiding on the edge of a protected area. Journal of Applied Ecology 49(5):1149-1158. http://dx.doi.org/10.1111/j.1365-2664.2012.02192.x

Guerbois, C., A.-B. Dufour, G. Mtare, and H. Fritz. 2013. Insights for integrated conservation from attitudes of people towards protected areas near Hwange National Park, Zimbabwe. Conservation Biology 27(4):844-855. http://dx.doi.org/10.1111/ cobi. 12108

Gurung, T. R., F. Bousquet, and G. Trébuil. 2006. Companion modeling, conflict resolution, and institution building: sharing irrigation water in the Lingmuteychu Watershed, Bhutan. Ecology and Society 11(2):36. http://dx.doi.org/10.5751/ es-01929-110236
International Union for Conservation of Nature (IUCN). 2003. The Durban Action Plan. Fifth IUCN World Parks Congress, Durban, South Africa, 8-17 September 2003. IUCN, Gland, Switzerland.

Leeuwis, C. 2000. Reconceptualizing participation for sustainable rural development: towards a negotiation approach. Development and Change 31(5):931-959. http://dx.doi.org/10.1111/1467-7660.00184

Le Page, C., N. Becu, P. Bommel, and F. Bousquet. 2012. Participatory agent-based simulation for renewable resource management: the role of the cormas simulation platform to nurture a community of practice. Journal of Artificial Societies and Social Simulation 15(1):10. http://dx.doi.org/10.18564/ jasss. 1928

Le Page, C., K. S. Bobo, O. W. T. Kamgaing, F. B. Ngahane, and M. Waltert. 2015. Interactive simulations with a stylized scale model to codesign with villagers an agent-based model of bushmeat hunting in the periphery of Korup National Park (Cameroon). Journal of Artifical Societies and Social Simulation 18(1):8. http://dx.doi.org/10.18564/jasss.2550

Lyamuya, R. D., E. H. Masenga, R. D. Fyumagwa, and E. Røskaft. 2014. Human-carnivore conflict over livestock in the eastern part of the Serengeti ecosystem, with a particular focus on the African wild dog Lycaon pictus. Oryx 48(3):378-384. http:// dx.doi.org/10.1017/s0030605312001706

Maciejewski, K., A. de Vos, G. S. Cumming, C. Moore, and D. Biggs. 2014. Cross-scale feedbacks and scale mismatches as influences on cultural services and the resilience of protected areas. Ecological Applications 25(1):11-23. http://dx.doi. org $/ 10.1890 / 13-2240.1$

MacKay, F., and E. Carison. 2004. Indigenous lands or national parks? Cultural Survival Quarterly 28(1):14.

Mannigel, E. 2008. Integrating parks and people: how does participation work in protected area management? Society and Natural Resources 21(6):498-511. http://dx.doi.org/https://doi. org/10.1080/08941920701618039

Maphosa, B. 1994. Lessons from the 1992 drought in Zimbabwe: the quest for alternative food policies. Nordic Journal of African Studies 3(1):53-58.

Matarira, C. ., and M. Jury. 1992. Contrasting meteorological structure of intra-seasonal wet and dry spells in Zimbabwe. International Journal of Climatology 12(2):165-176. http://dx.doi. org/10.1002/joc.3370120205

Matema, S., and J. A. Andersson. 2015. Why are lions killing us? Human-wildlife conflict and social discontent in Mbire District, northern Zimbabwe. The Journal of Modern African Studies 53 (1):93-120. http://dx.doi.org/10.1017/s0022278x14000664

Mathevet, R., M. Antona, C. Barnaud, C. Fourrage, G. Trébuil, and S. Aubert. 2011. Contexts and dependencies in the ComMod process. Pages 141-167 in M. Étienne, editor. Companion modelling. A participatory approach to support sustainable development. Éditions Quae, Versailles, France.

Mathevet, R., C. Le Page, M. Étienne, G. Lefebvre, B. Poulin, G. Gigot, S. Proreol, and A. Mauchamp. 2007. BUTORSTAR: a role-playing game for collective awareness of wise reedbed use. Simulation and Gaming 38(2):233-262 http://dx.doi. org/10.1177/1046878107300665 
Mathevet, R., J. D. Thompson, C. Folke, and F. S. Chapin. 2016. Protected areas and their surrounding territory: socioecological systems in the context of ecological solidarity. Ecological Applications 26(1):5-16. http://dx.doi.org/10.1890/14-0421

McGinnis, M. D., and E. Ostrom. 2014. Social-ecological system framework: initial changes and continuing challenges. Ecology and Society 19(2):30. http://dx.doi.org/10.5751/es-06387-190230

Metcalfe, S., and T. Kepe. 2008. "Your elephant on our land": the struggle to manage wildlife mobility on Zambian communal land in the Kavango-Zambezi Transfrontier Conservation Area. The Journal of Environment and Development 17(2):99-117. http://dx. doi.org/10.1177/1070496508315733

Muboko, N., V. Muposhi, T. Tarakini, E. Gandiwa, S. Vengesayi, and E. Makuwe. 2014. Cyanide poisoning and African elephant mortality in Hwange National Park, Zimbabwe: a preliminary assessment. Pachyderm(55):92-94.

Murphree, M. 2013. Foreword. Pages 1-11 in J. A. Andersson, M. de Garine-Wichatitsky, D. H. M. Cumming, V. Dzingirai and K. E. Giller, editors. Transfrontier conservation area: people living on the edge. Earthscan, Routledge, London, UK; New York, New York, USA.

Ncube, G. 2004. A history of northwestern Zimbabwe, 1850-1960. Mond Books, Kadoma, Zimbabwe.

Ndaimani, H., P. Tagwireyi, L. Sebele, and H. Madzikanda. 2016. An ecological paradox: the African wild dog (Lycaon pictus) is not attracted to water points when water is scarce in Hwange National Park, Zimbabwe. PloS one 11(1):e0146263. http://dx. doi.org/10.1371/journal.pone.0146263

Nelson, M. P., J. T. Bruskotter, J. A. Vucetich, and G. Chapron. 2016. Emotions and the ethics of consequence in conservation decisions: lessons from Cecil the lion. Conservation Letters 9 (4):302-306. http://dx.doi.org/10.1111/conl.12232

Newmark, W. D., and J. L. Hough. 2000. Conserving wildlife in Africa: integrated conservation and development projects and beyond because multiple factors hinder integrated conservation and development projects in Africa from achieving their objectives, alternative and complementary approaches for promoting wildlife conservation must be actively explored. BioScience 50(7):585-592.

Orlove, B. 2002. Lines in the water: nature and culture at Lake Titicaca. University of California Press, Berkeley, California, USA.

Pahl-Wostl, C. 2007. The implications of complexity for integrated resources management. Environmental Modelling and Software 22(5):561-569. http://dx.doi.org/10.1016/j.envsoft.2005.12.024

Palomo, I., C. Montes, B. Martin-Lopez, J. A. Gonzalez, M. Garcia-Llorente, P. Alcorlo, and M. R. G. Mora. 2014. Incorporating the social-ecological approach in protected areas in the Anthropocene. BioScience 64(3):181-191. http://dx.doi. org/10.1093/biosci/bit033

Parker, D. C., S. M. Manson, M. A. Janssen, M. J. Hoffmann, and P. Deadman. 2003. Multi-agent systems for the simulation of land-use and land-cover change: a review. Annals of the
Association of American Geographers 93(2):314-337. http://dx. doi.org/10.1111/1467-8306.9302004

Perrotton, A. 2015. Cattle herding and coexistence between protected areas and their peripheries: a participatory approach. Montpellier2/Center for Applied Social Sciences, Montpellier, France; Harare, Zimbabwe.

Queste, J., F. Bousquet, T. R. Gurung, and G. Trebuil. 2011. Jeux de rôles comme objets frontières dans un conflit de partage de l'eau d'irrigation au Bouthan. Cahiers Agricultures 20:118-123.

Rowcliffe, J. ., E. de Merode, and G. Cowlishaw. 2004. Do wildlife laws work? Species protection and the application of a prey choice model to poaching decisions. Proceedings of the Royal Society of London 271(1557). http://dx.doi.org/10.1098/rspb.2004.2915

Souchère, V., L. Millair, J. Echeverria, F. Bousquet, C. Le Page, and M. Étienne. 2010. Co-constructing with stakeholders a roleplaying game to initiate collective management of erosive runoff risks at the watershed scale. Environmental Modelling and Software 25(11):1359-1370. http://dx.doi.org/10.1016/j. envsoft.2009.03.002

Stern, M. J. 2008. The power of trust: toward a theory of local opposition to neighboring protected areas. Society and Natural Resources 21(10):859-875. http://dx.doi.org/10.1080/08941920801973763

Stokes, S., D. S. G. Thomas, and R. Washington. 1997. Multiple episodes of aridity in southern Africa since the last interglacial period. Nature 388(6638):154-158. http://dx.doi.org/https://doi. org/10.1038/40596

Stringer, L. C., A. J. Dougill, E. Fraser, K. Hubacek, C. Prell, and M. S. Reed. 2006. Unpacking "participation" in the adaptive management of social-ecological systems: a critical review. Ecology and Society 11(2):39. http://dx.doi.org/https://doi. org/10.5751/ES-01896-110239

Sun, Z., I. Lorscheid, J. D. Millington, S. Lauf, N. R. Magliocca, J. Groeneveld, S. Balbi, H. Nolzen, B. Müller, J. Schulze, and C. M. Buchmann. 2016. Simple or complicated agent-based models? A complicated issue. Environmental Modelling and Software 86:56-67. http://dx.doi.org/10.1016/j.envsoft.2016.09.006

Susskind, L., A. E. Camacho, and T. Schenk. 2012. A critical assessment of collaborative adaptive management in practice: collaborative adaptive management. Journal of Applied Ecology 49(1):47-51. http://dx.doi.org/10.1111/j.1365-2664.2011.02070. $\underline{\mathrm{x}}$

Valls-Fox, H. 2015. To drink or not to drink? The influence of resource availability on elephant foraging and habitat selection in a semi-arid savanna. Montpellier 2, Montpellier, France.

Verweijen, J., and E. Marijnen. 2016. The counterinsurgency/ conservation nexus: guerrilla livelihoods and the dynamics of conflict and violence in the Virunga National Park, Democratic Republic of the Congo. The Journal of Peasant Studies 0(0):1-21. http://dx.doi.org/10.1080/03066150.2016.1203307

Vinck, D. 2009. De l'objet intermédiaire à l'objet-frontière: vers la prise en compte du travail d'équipement. Revue d'anthropologie des connaissances 3, 1(1):51. http://dx.doi.org/10.3917/rac.006.0051 
Walker, W. E., P. Harremoës, J. Rotmans, J. P. van der Sluijs, M. B. A. van Asselt, P. Janssen, and M. P. K. von Krauss. 2003. Defining uncertainty: a conceptual basis for uncertainty management in model-based decision support. Integrated Assessment 4(1):5-17. http://dx.doi.org/10.1076/iaij.4.1.5.16466

Weick, K. E. 1995. Sensemaking in organizations. Sage Publications, Thousand Oaks, California, USA.

Wells, M. P., and T. O. McShane. 2004. Integrating protected area management with local needs and aspirations. AMBIO: A Journal of the Human Environment 33(8):513-519. http://dx.doi. org/10.1579/0044-7447-33.8.513

West, P., J. Igoe, and D. Brockington. 2006. Parks and peoples: the social impact of protected areas. Annual Review of Anthropology 35(1):251-277. http://dx.doi.org/10.1146/annurev. anthro.35.081705.123308

Wittmer, H., F. Rauschmayer, and B. Klauer. 2006. How to select instruments for the resolution of environmental conflicts? Land Use Policy 23(1):1-9. http://dx.doi.org/https://doi.org/10.1016/j. landusepol.2004.09.003 


\section{Appendix 1. Kulayinjana, Overview-Design-Details (ODD)}

The description of the model is based on the updated version (Grimm et al. 2010) of the ODD protocol that was originally proposed by Grimm and his colleagues in 2006. The model was uploaded on https://www.openabm.org/model/5221.

\section{Purpose}

The purpose of the game is to bring players to incarnate farmers in a virtual environment mimicking their reality, and to collectively learn about the use of the landscape through cattle herding.

\section{Entities, state variables and scales}

$\underline{\text { Cells }}$ are the elementary spatial entities of the model. The whole space is divided in two Zones, the first one representing Communal Land and the other representing Forest. Some forage is available in both zones.

In the model, a Household is either controlled by a human player (played household) or connected by the computer to a played household (computerized farm; it then behaves as a clone). In the communal land, Households manage Farms. A farm is made up of an

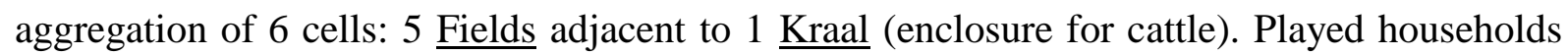
own $\underline{\text { Cattle, }}$, an initial herd of 5 Cows that can be guarded by a Herdboy while grazing. Each Cow has a status (thin, medium or fat) that changes over time according to how the cow fed.

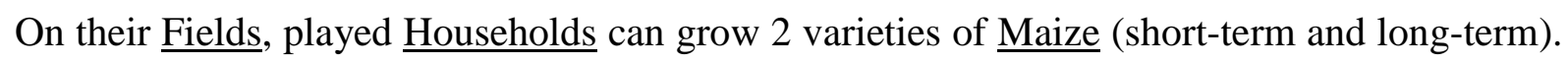
When harvested, crop leftovers, called Machanga, represent a source of food for the cows.

GrazingAreas (also called paddocks) represent the management units for cattle herding in the model. Grazing areas are aggregates of cells. There are 4 grazing areas in the Communal Land and 9 grazing areas in the Forest. The level of forage of each grazing area is null, depleted, medium or good. It changes according to the load of cattle, the season and the rainfall. Some grazing areas have Waterpans. When these water pans are not dried out, they are used by the cows located there.

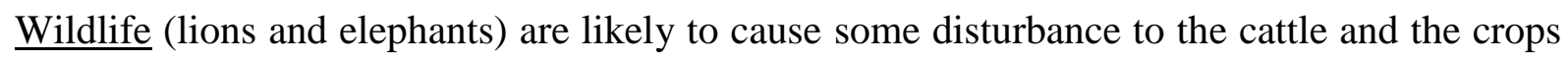
of the households.

An overview of the overall structure of the model is provided by a UML class diagram (see figure 1). 


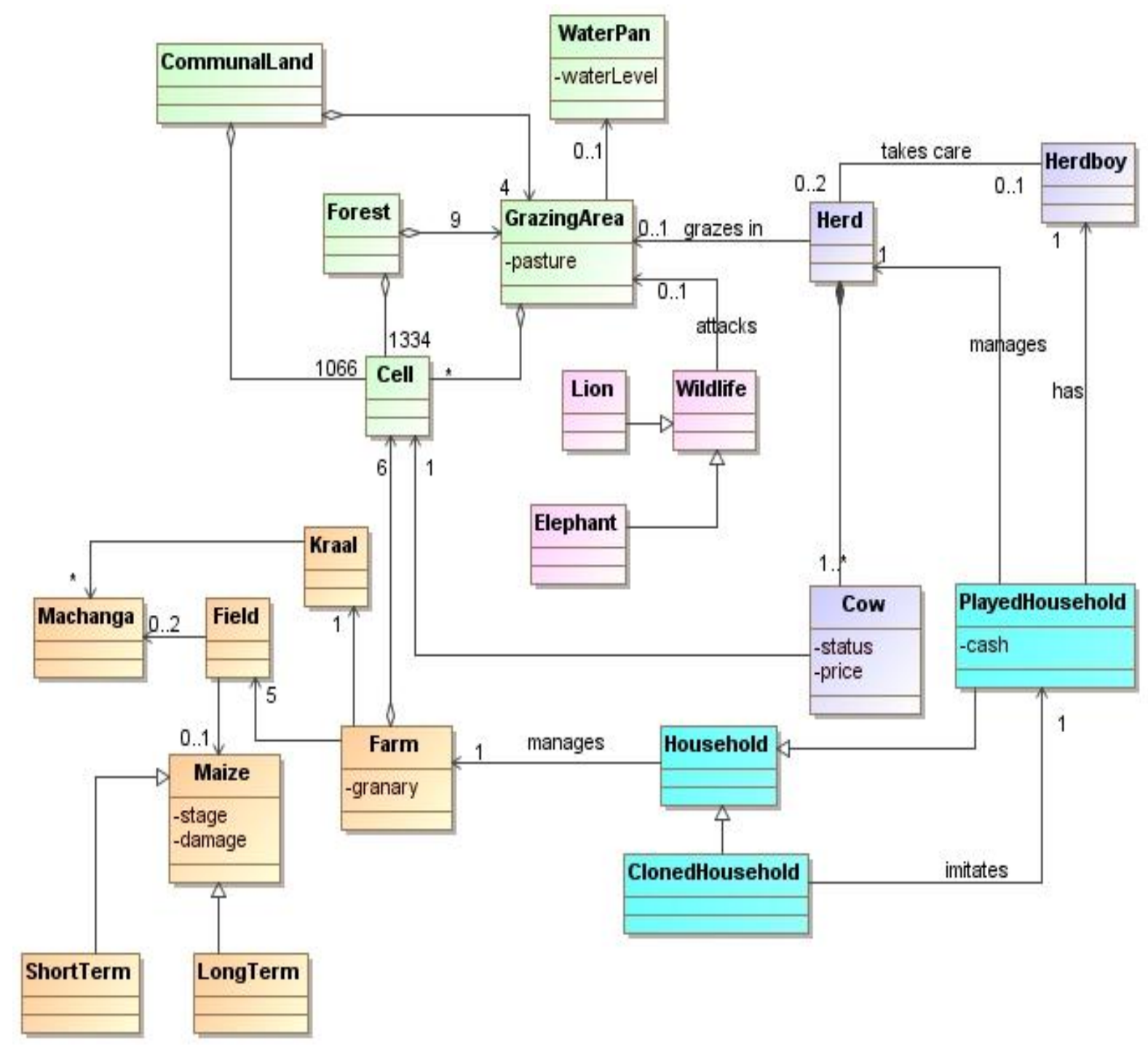

Figure 1. Class diagram of the Kulayinjana model.

Players have two objects of decision making at the beginning of each month: their

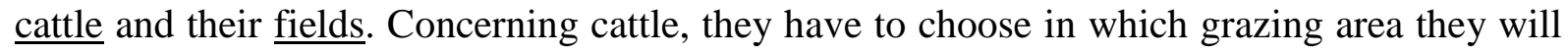
graze, and if they will be guarded or not, that is if they put a herdboy with the herd or not ${ }^{1}$. At the beginning of the month, players can also decide to buy or sell cattle. Concerning their $\underline{\text { fields, }}$ at the beginning of each month players can decide to plow or harvest their fields. Fields can only be harvested if the maize is either mature or dry, but in the first case, harvesting implies building a granary for the maize to dry up.

\footnotetext{
${ }^{1}$ In the area, cows are usually grazing during the day, and gathered in the kraal at night we're the Kraal serves as a protection. In the model (and in the game), only active phases of cattle herding are considered, and nights are not simulated.
} 
All of these actions obey specific cost/benefit rules. These rely on tokens that are distributed to, or given back by players. There are two types of tokens, small ones (ST) and big ones (BT). A big token equals six small ones. The balance of tokens is stored in households' cashboxes. The main parameters of the model are listed in table 1 . The way these parameters affect the various processes is explained in the "details" subsection (last part of the ODD protocol).

\begin{tabular}{|c|c|c|c|}
\hline Entity & Parameter & Value & Unit \\
\hline GrazingArea & $\begin{array}{l}\text { cattleOverloadThreshold } \\
\text { protectionAtNightAgainstElephants }\end{array}$ & $\begin{array}{c}10 \\
3\end{array}$ & $\begin{array}{l}\text { cow } \\
\text { small token }\end{array}$ \\
\hline Cow & $\begin{array}{l}\text { fatteningThreshold } \\
\text { wastingThreshold } \\
\text { marketPrice_Fat } \\
\text { marketPrice_Medium } \\
\text { marketPrice_Thin }\end{array}$ & $\begin{array}{c}6 \\
3 \\
18 \\
12 \\
6\end{array}$ & $\begin{array}{l}\text { satiation index } \\
\text { satiation index } \\
\text { small token } \\
\text { small token } \\
\text { small token }\end{array}$ \\
\hline Cattle & $\begin{array}{l}\text { herdboyCost } \\
\text { grazingAreaCrossingCost } \\
\text { wateringCost } \\
\text { damageMaize_Cattle }\end{array}$ & $\begin{array}{c}1 \\
1 \\
1 \\
25 \%\end{array}$ & $\begin{array}{l}\text { small token } \\
\text { small token } \\
\text { small token } \\
\text { expected yield }\end{array}$ \\
\hline Wildlife & damageMaize_Elelephant & $50 \%$ & expected yield \\
\hline Maize & $\begin{array}{l}\text { damageMaize_Climate } \\
\text { establishmentCost } \\
\text { yieldIncome } \\
\text { Machanga } \\
\text { machangaFeedingCapacity }\end{array}$ & $\begin{array}{c}100 \% \\
6 \\
12 \\
2 \\
1\end{array}$ & $\begin{array}{l}\text { expected yield } \\
\text { small token } \\
\text { small token } \\
\text { small token } \\
\text { satiation index }\end{array}$ \\
\hline Household & initialCashbox & 48 & small token \\
\hline Farm & granaryCost & 1 & small token \\
\hline
\end{tabular}

Table 1. Model parameters. 
The time step of the model $^{2}$ represents one day. The game covers two agricultural years, from the beginning of October (year $\left.{ }_{1}\right)$ to the end of September (year $\left.{ }_{2}\right)$. Players' decisions are done only at the beginning of the month. To complete a game session, 24 rounds of decisions have therefore to be achieved. The virtual environment (Fig.2) referred to as "the map" is a grid of $60 * 40$ square cells. The size of a cell was defined by the design team so that one cell represents one "umfollow", that is the surface that one farmer can plough in one day. Therefore, the cells' area is 0.5 acre $(45 \mathrm{~m} * 45 \mathrm{~m})$. The total surface covered by our virtual environment is 2400 cells, that is 1200 acres.

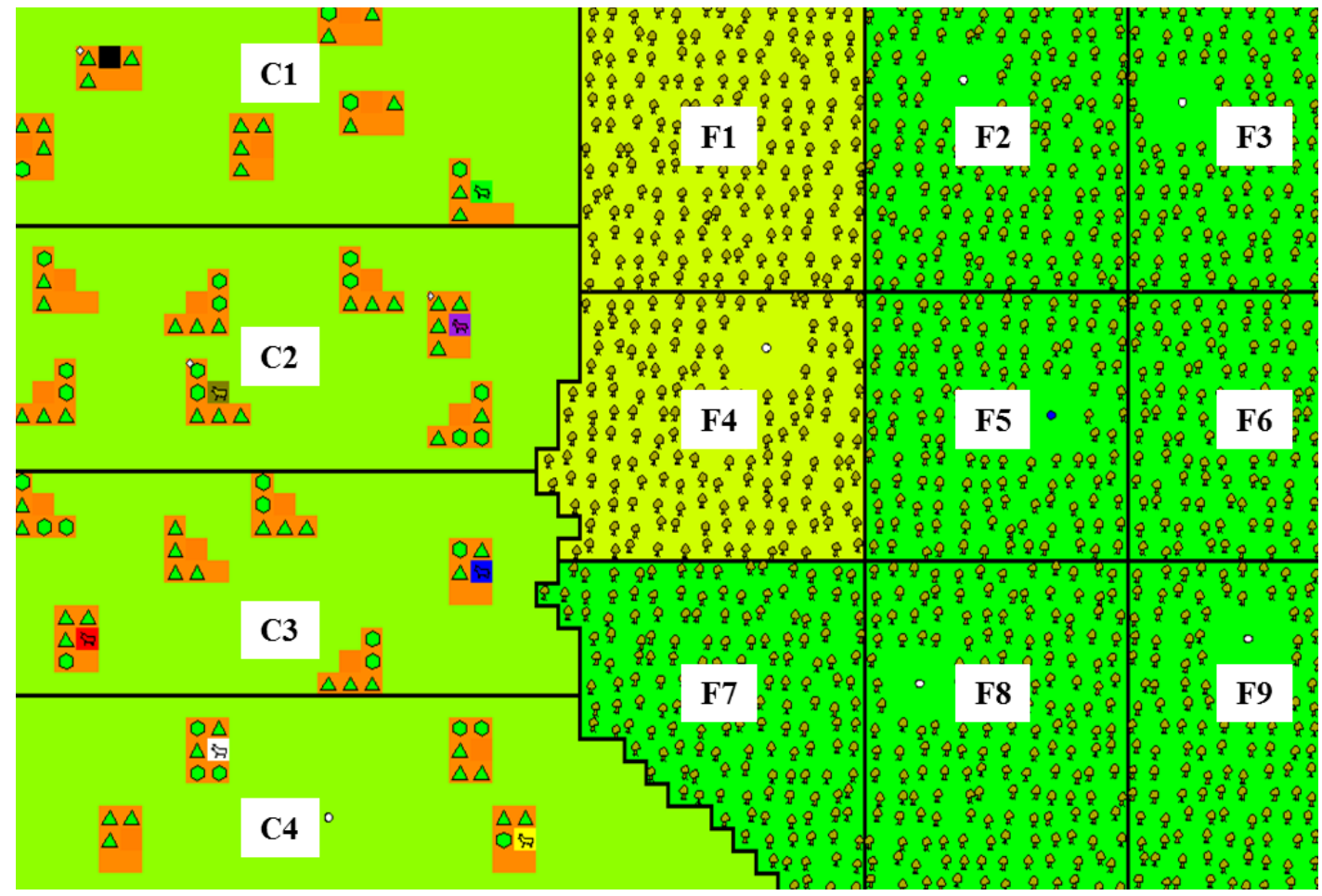

Figure 2. The virtual environment. The virtual environment is divided in 13 GrazingAreas numbered $\mathrm{Cl}$ to $\mathrm{C} 4 \mathrm{in}$ the communal land, F1 to F9 in the forest. Each played Farm has its Kraal colored according to the player in charge ( 2 played Farms by communal GrazingArea), the 5 fields appearing in orange ( 5 orange cells around the Kraal). Farms with no Kraal are clones managed by the model. The green entities seen on fields represent growing Crops (triangles are short term maize; rounds are long term maize). _The figure shows three of the four different forage levels: "poor" (F1 and F4); "medium" (C1 to C4). and "good" (F2, F3, F5, F6, F7, F8 and F9). These levels change during the game according to players' actions.

\section{Process overview and scheduling}

\footnotetext{
${ }^{2}$ The playing time step is a month, that is that players make their decisions at the beginning of the month. The model supporting the game has a daily time step. In other words, the model does 30 time steps between each round.
} 
The model presented here supports a role-playing game and as a result, is not run "continuously", but is stopped and resumed for players to make their decisions (Fig.3).

At the beginning of the game, players choose from predefined locations which farm they want to manage. Then the simulation is scheduled by month.

At the beginning of the month, a weather forecast is given for the first week. Players notify with pawns if they want to plant Maize. Players put a pawn on each field they want to plow, knowing that each field can only have one growing Maize at a time. There are two types of pawn, corresponding to the two type of Maize. If some of the Maize is ready to be harvested, the players can choose to harvest. In that case, they have to notify if they leave the crop residue in the field (can be used by any Cattle), or if the crop residues are stored within the

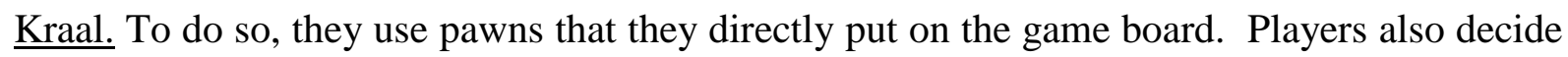

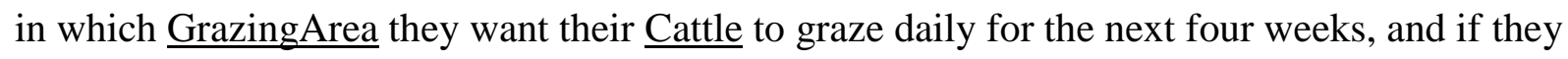
will be guarded by a Herdboy ${ }^{3}$.

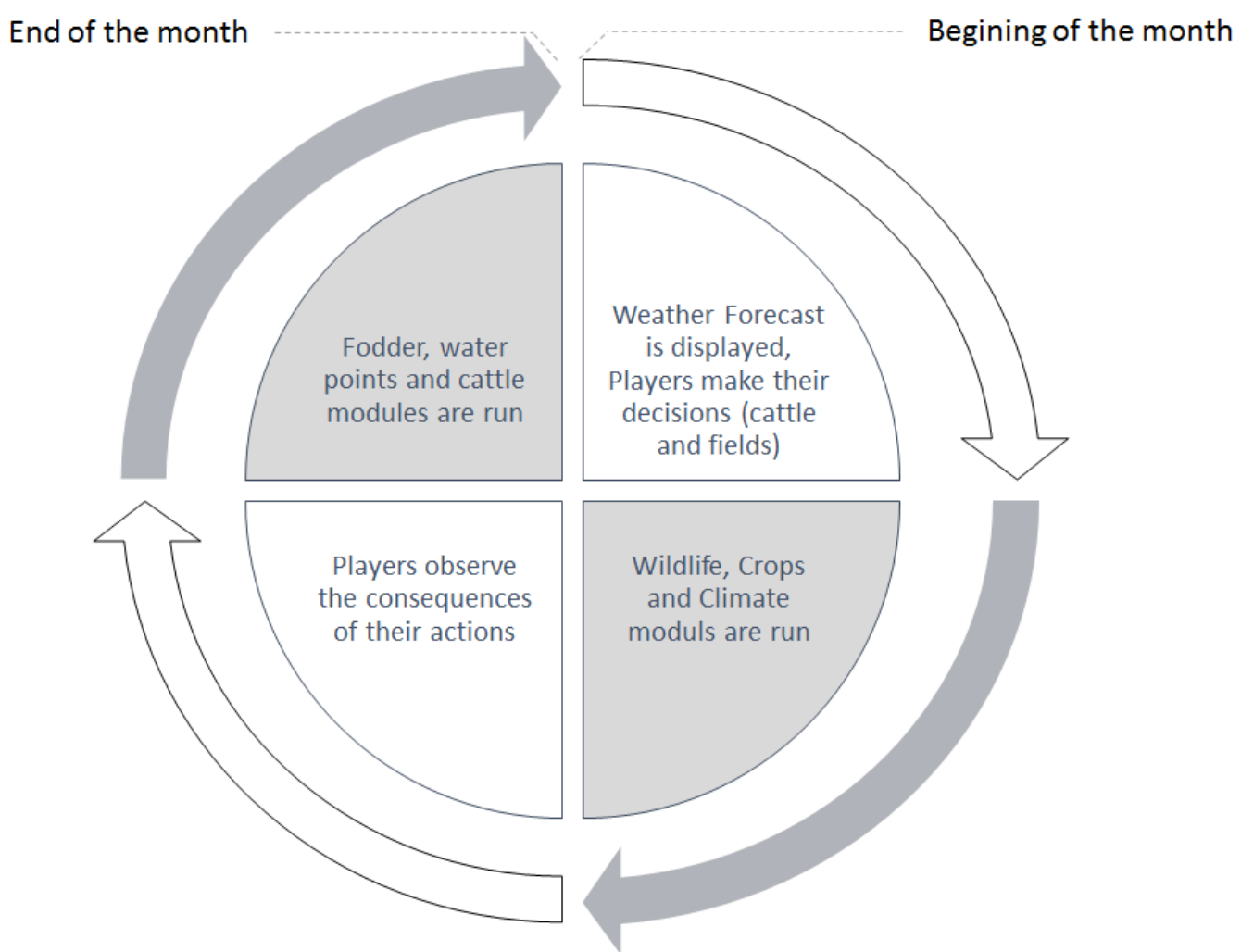

Figure 3. Sequential mobilization of the modules during the playing session. A round of playing, that is a month in the model, is done in four steps. Grey phases represent moments were the model is run, white phases are moments when the model is paused. The model is constituted of different modules, controlling specific dynamics (see next paragraphs). These modules are mobilized at specific steps of the month, as showed by the figure.

\footnotetext{
${ }^{3}$ See foot note 71 .
} 
Once all the decisions are entered by the computer operator (Fig. 4), the model is run for 30 time steps (a month).

During the month, the climate is updated weekly. Players have access to a table displayed in the game's interface where the amount of rain is retrospectively shown (Fig. 5). Maize entities are updated daily (Fig. 8) by the computer (stages, failures).

At the end of the month, the Cattle damage module is run (cattle entering fields); the Wildlife module is run (lion attack and elephant crop raiding); Cattle statuses are updated according to the forage level of the GrazingArea they were using; the forage of every GrazingArea is updated. The number of cattle owned by players is updated along with cattle conditions. So are the sizes of Waterpans. Finally, the cashboxes of the 8 played households are updated.

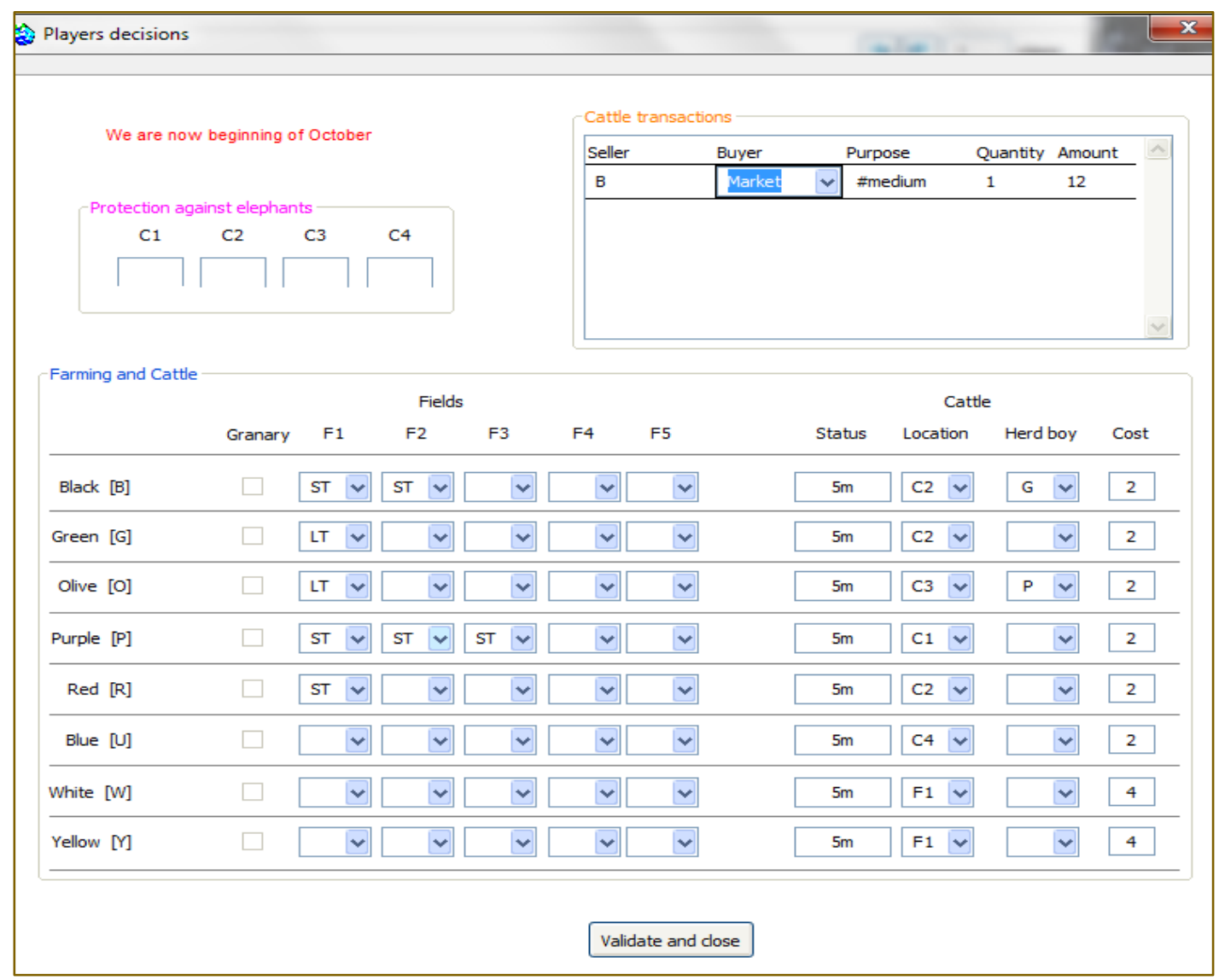

Figure 5.4. Interface used by the computer operator to enter players' decisions at the beginning of each month. The "protection against elephants" can be filled with the initials of the players paying to protect a communal GrazingArea (in this case no one protected any). The "cattle transaction" box deals with cattle sales and purchases (here the Black player sold a medium cow to the market and earned 12ST). The "Farming and Cattle" relates to crops and cattle herding. Here for instance, the black players decided to plant two of his fields with short-term maize and to put his Cattle -guarded by the Green herdboy-in C2. 


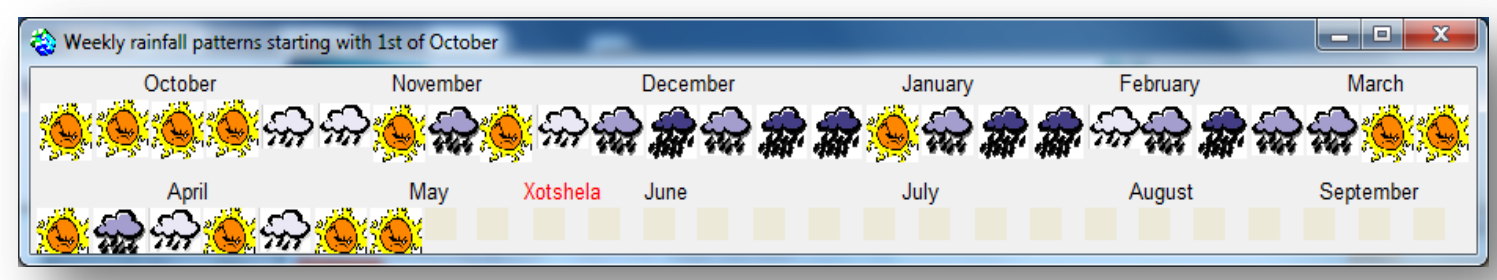

Figure 5. The weekly rainfall calendar. The sun corresponds to a dry week, a light cloud represents 5-20mm of rain, a grey cloud represents 20-40mm of rain, the dark cloud represents $+40 \mathrm{~mm}$ of rainfall. The first of June is indicated as xotshela, a Ndebele word meaning "to push", that corresponds to the historical traditional date when cattle are released freely in the fields to eat the crops leftovers.

\section{Design Concepts}

The game was co-designed by researchers and representatives of the local community studied, with the objective of proposing a role-playing game mimicking local for players to reproduce their actual practices. The agents' behavior is not programmed, but is left open for players to make choices. The consequences of players' decisions are public. The players can therefore learn and adapt.

We assume that players make, to a certain extent, their decision following the same rationale they would use in the real life. The extent to which they reproduce their actual practices is assessed through a post-playing questionnaire.

Uncertainty is part of the model supporting the game. Wildlife actions for instance are based on probabilities, and players must consider risks while managing their cattle and fields. Similarly, when they have to make decisions, players do not know in advance the rainfalls of the coming month, except for the first week that is announced with a "weather forecast". Assessing the way players deal with such uncertainties is one of the objectives of the game.

Being implemented as a role-playing game, interactions among agents are central. Players are free to talk during the gaming session, including talking together to advise or seek advice, congratulating or mocking, coordinating or working together. In particular, they can make 
agreements to share the cost of guarding their cattle and the cost of guarding their communal paddock at night to prevent crop raiding by elephants.

The played households have similar characteristics at the beginning of the game. The players manipulate or own the same entities (5 fields, 5 cows) and have the same initial number of tokens. Nevertheless, we assume that a diversity of strategies and objectives will be exhibited during the gaming sessions, reflecting heterogeneity in the decision-making processes and objectives among the participants. Eliciting player's strategies and objectives and relating them to their strategies and objectives in their "real-life" is the heart of the post-game debriefing.

Some stochasticity is found in the Wildlife and the Cattle damage modules. The same predetermined sets of "random" events are used for each gaming session. standardizing the randomness is needed to ensure the comparability of the playing sessions.

The observation of the gaming sessions is supported by the use of the computer. Every playing decision is recorded, along with environmental parameters. Furthermore, supplementary information can be extracted from playing sessions through the replay function of the simulation platform used (CORMAS). Additionally, a member of the facilitation team records social interactions by taking pictures and collecting minutes later on organized in snippets of conversation relevant to various themes to be discussed during the post-game debriefing. After playing, questionnaires are administered to all participants.

\section{Implementation details}

The model was developed through several participatory workshops. The computer part was implemented with the Cormas simulation platform. The game was played 4 times and the playing sessions involved a total of 22 players.

\section{Initialization of the simulation}

The initialization of the simulation was always the same. The model is initiated at the beginning of October. All the farms, played (8) and cloned (15), are located by default. There are two played farms in each communal GrazingArea (Fig.6). Thanks to a name-drawing system, each participant in the playing session is asked to choose which Farm he wants to manage. Each players receives an initial cashbox of 48 small tokens (ST) that he will use to play (plant, drive his cattle, etc). Finally, each player starts with a Cattle herd of five medium 
Cows. At the start, communal and forest GrazingAreas all have "medium" forage. All the herds are in their respective Kraals, and all Waterpans are empty, except the one located on F5.

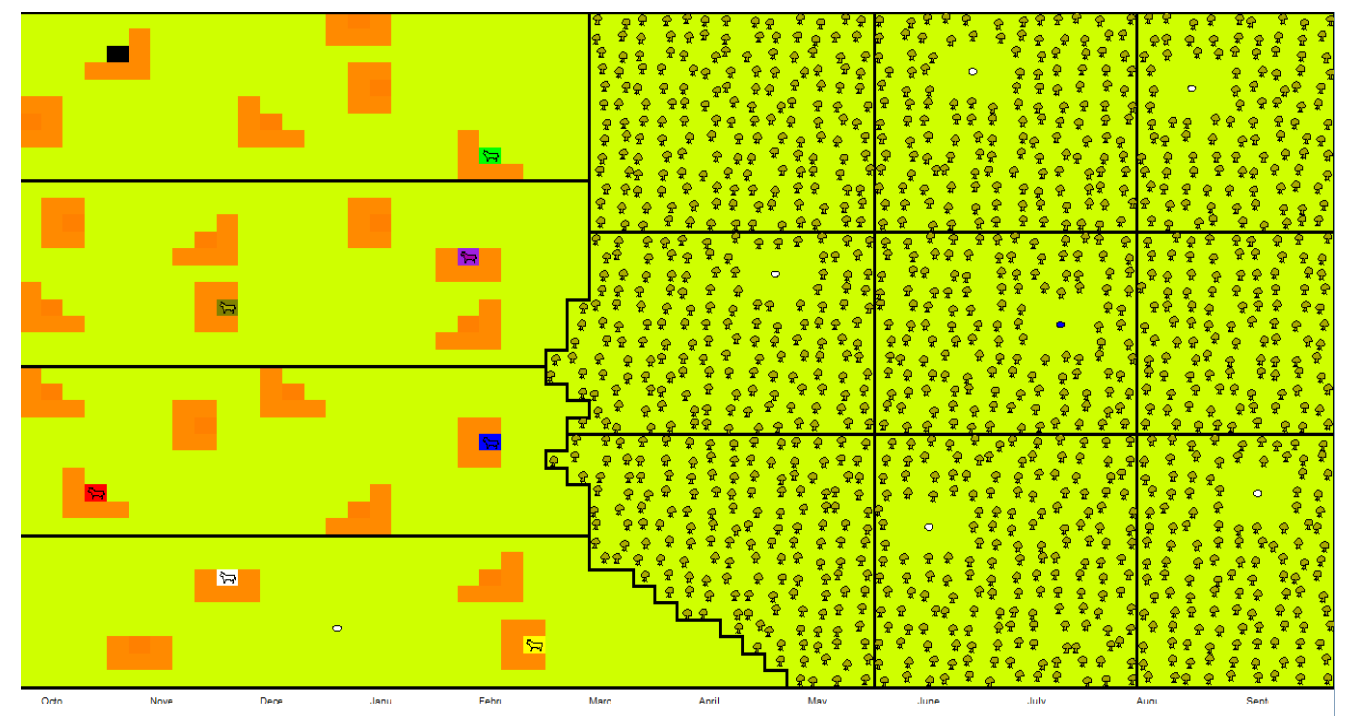

Figure 6. The virtual environment at the initiation of the model/playing session.

\section{Input data}

The model used weekly rainfall input data. Rainfall records were obtained in the study area. Two contrasted climatic years (Fig. 7) were used to produce a continuous 2-year dataset: a first "good year" (2012-13), measured by ourselves in the study area, is followed by a "bad year" (data from 1920-21), measured in the study area by the Rhodesian meteorological services. As showed in figure 5, the two sets of empirical data used for the rain sub-model propose very contrasted climatic conditions. The "good rains" year is characterized by abundant rainfall throughout the rainy season, with a total of $733 \mathrm{~mm}$, while the "bad rains" year only offers $531 \mathrm{~mm}$ through erratic and low rainfall. This weekly rainfall was transformed into four types of week (Fig.5.5): "dry" $(<5 \mathrm{~mm})$; small rain $(<20 \mathrm{~mm})$; "medium rains" (20 to 40mm); "big rains" ( $>40 \mathrm{~mm})$. 


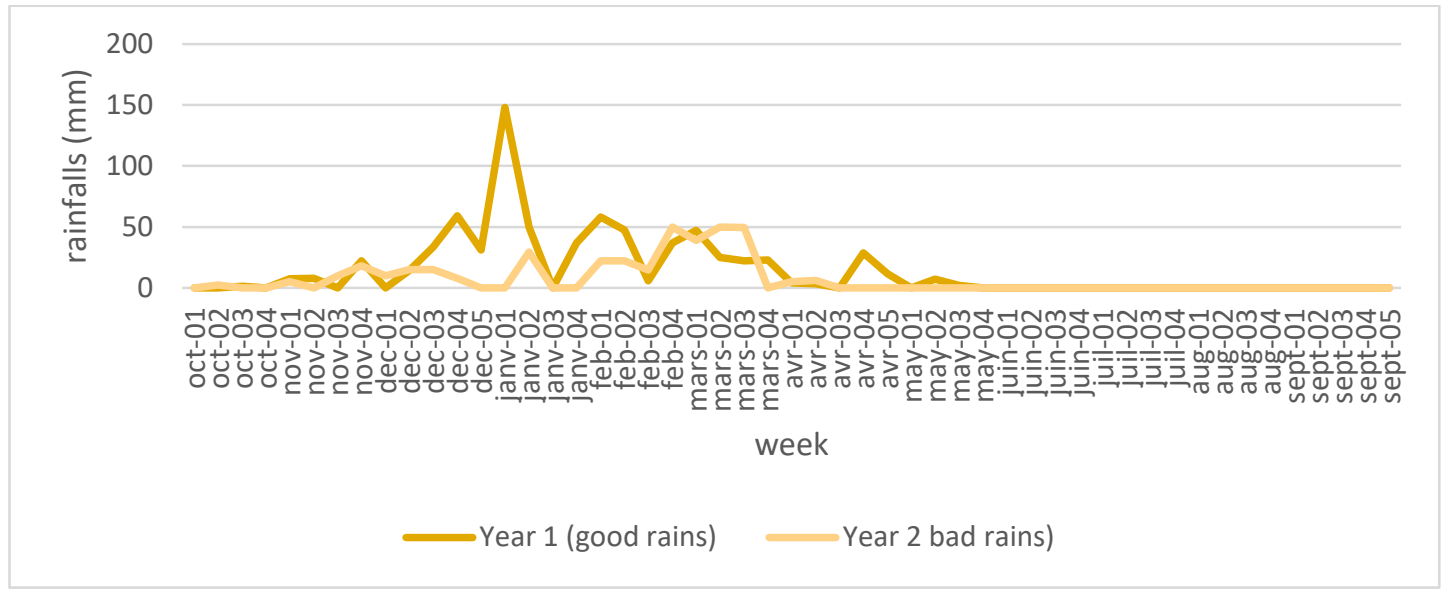

Figure 7. Weekly rainfall data. The figure shows the two sets of data used for the rain module.

\section{Details for crop sub-model}

This module controls crops dynamics and weather-related failures. There are two types of Crop. They have the same productivity, but differ by their growing dynamics. Once planted (stage: seed), both short-term and long-term types germinate after the first non-dry week (stage: germinated) and remain in that stage -prone to rain washing- for two months, until they evolve to the "shooting" status. Crop types differ by the time needed to change from the stage shooting to the stage mature: 1 month for the short-term variety against 2 months for the long-term variety. The transition diagrams are represented in figure 8. Players can harvest their crops when they are either "mature" or "dry". Nevertheless, when players harvest "mature" crops they must build a granary, unless they already have one.

Crops are sensitive to drought. Between the moment they are planted and the end of December, three consecutive weeks without rain cause a loss of $100 \%$ of every growing shortterm crop. Long-term crops are more resistant: they need four weeks of drought to be destroyed. On the other hand, during the germinated stage of development, crops are also sensitive to floods, and both types will be destroyed (100\%) by three consecutive weeks of heavy rains. 
LONG-TERM

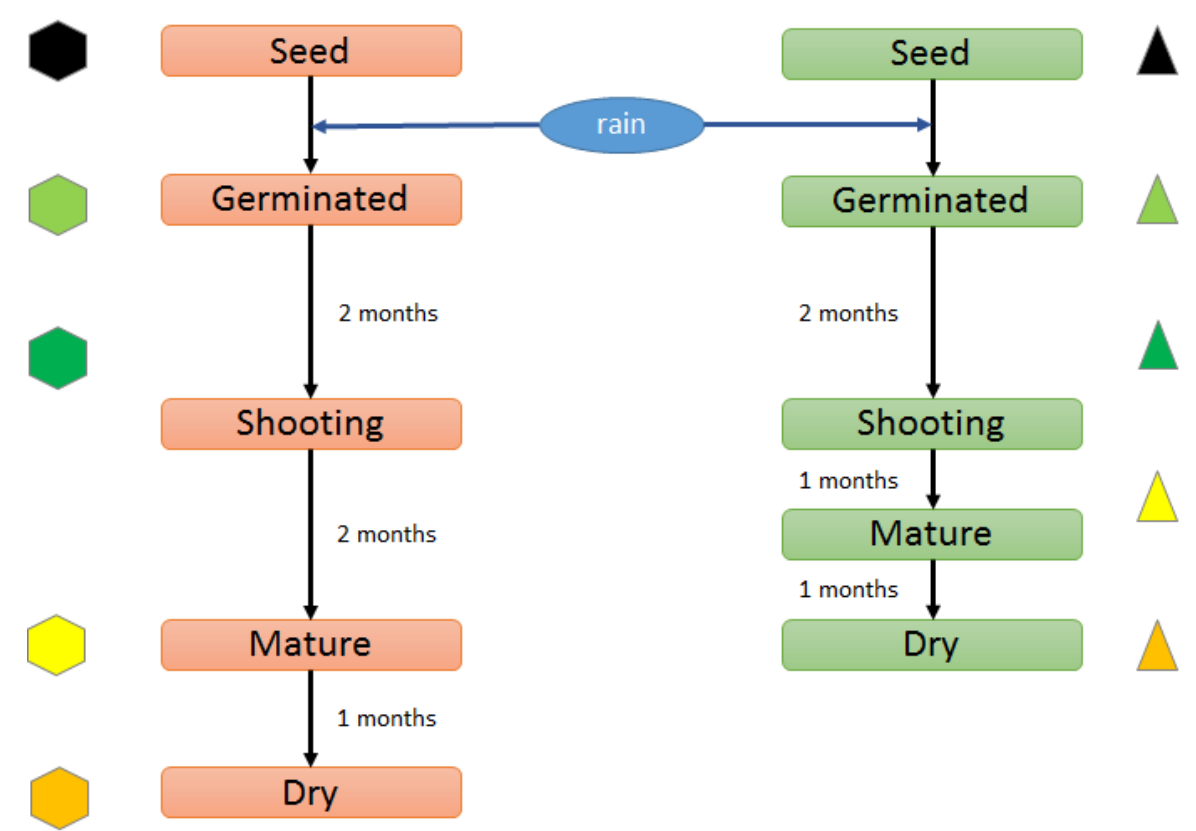

Figure 8. Crops transition diagrams.

\section{Details for elephant damages}

The module related to damages made by wild herbivores (only elephants are represented in the model) to crops is run at the level of grazing areas. Each month, grazing areas that are not protected by players and containing at least one field with a mature maize have 94/100 chances of being attacked by elephants. When elephants attack, all the farms are not impacted the same way. The first line of farms (Fig.9) will have up to three fields damaged, whereas the other farms of the grazing area will only have one field attacked. An attack will cause a loss of $50 \%$ of the yields. By protecting their grazing area, players decrease the chances of having elephants attacking to 6/100. Attack of Elephants are represented on the visual interface of the game (Fig. 9), and losses caused by elephants are represented by a blue diamond on the corner of each attacked field. 


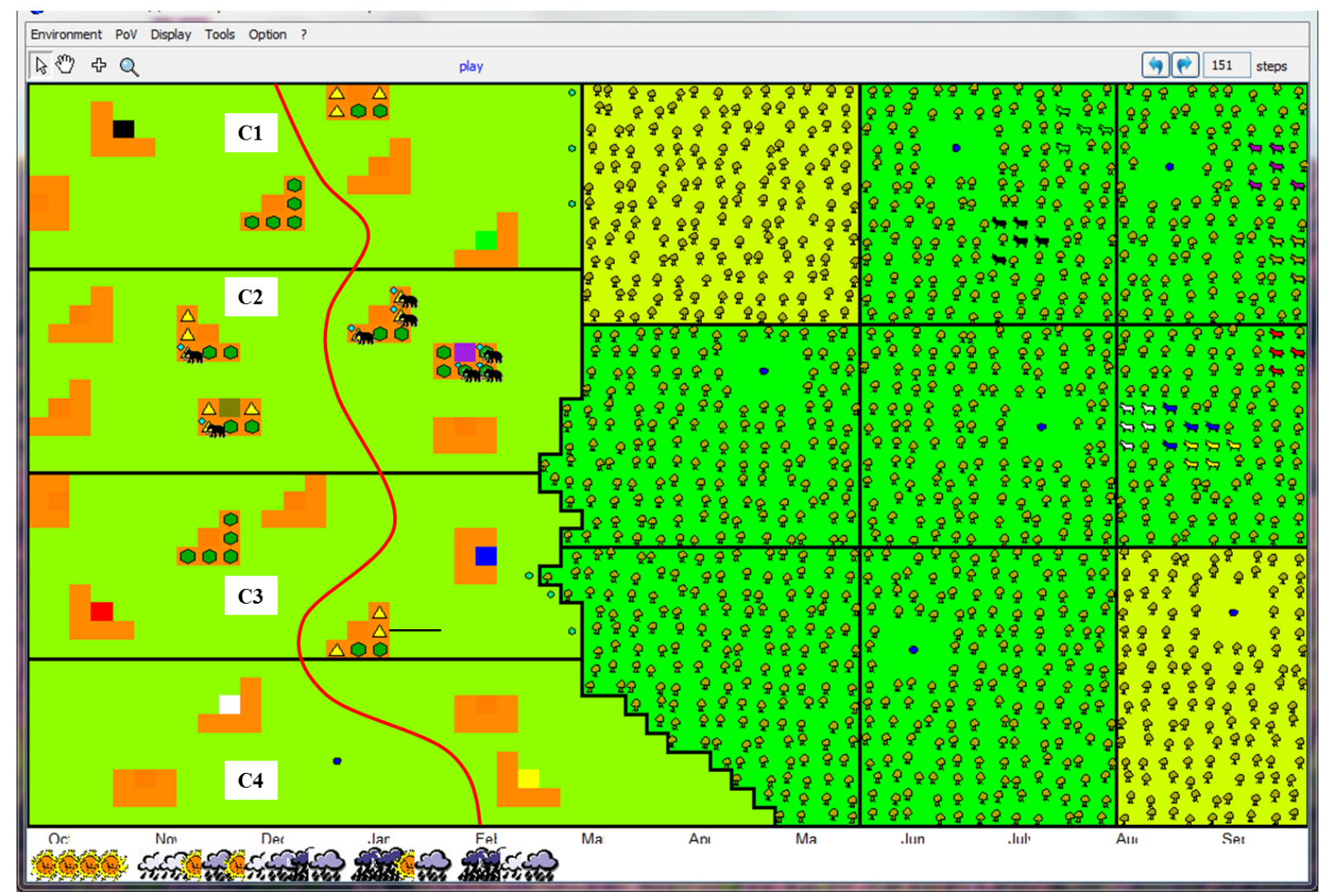

Figure 9. Elephants' damages. Grazing areas with mature maize (here C1, C2 and C3) are prone to crop raiding by elephants. $C 2$, which was not guarded (no small green circles at the edge between the communal land and the forest) was attacked by elephants. Farms located on the right side of the red line are considered as the first line of farms. These farms are more heavily impacted by the attack.

\section{Details for cattle damages}

In the paper, we described the rule according to which cattle cannot be released freely in the village before a particular date: Xotshela (usually the $1^{\text {st }}$ of June). Nevertheless, it was collectively agreed that the game would contain no enforcing mechanisms, but that the players themselves would be free to discuss, apply and respect this rule or not during the game. Therefore, in the model supporting the game, cattle can graze anywhere anytime and when grazing in the communal area during the agricultural season, cattle entities can enter 
fields and cause agricultural loses if these contain crops. Unguarded cattle (without herdboy) will enter a randomly picked field with growing maize, and cause $25 \%$ loss of the yield the owner would have get from the maize entity growing there. Repeated loses caused by cattle or wildlife will ultimately destroy maize entities. A given cattle can enter only one field per month. Once the module is run, the visual interface is updated: a message is displayed on the game's interface to inform the players: "Player ... your cattle entered the field of player..."; the cattle entity is displayed on the field it entered and the losses are represented on the field (Fig.10); the loses are stored and the yields the player will get when he harvests are modified.

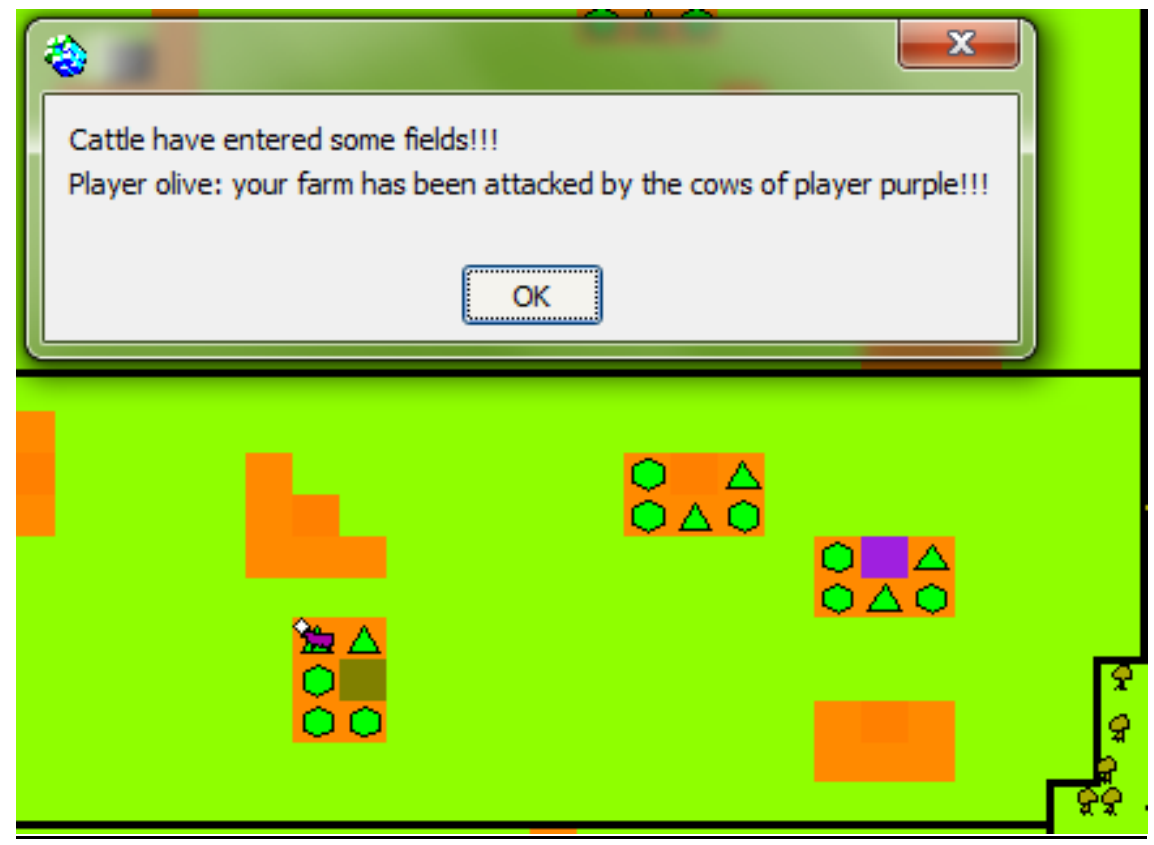

Figure 10. Cattle entering a Field. The cattle of the purple player were left alone to graze in this communal paddock containing growing fields. They entered a growing field of the olive player. The white lozenge on the corner of the field of the olive player signifies a loss of $25 \%$.

\section{Details for cattle status dynamics}

Every month, the level of satiation $(0,1$ or 2$)$ of a cow is determined accordingly to the level of forage of the grazing area where the cow was located. When cows are feeding on crop residues (machanga), the satiation is set to the number of machanga eaten (max. 2). The status of a cow depends on how it fed during the last three months: when its accumulated 
satiation is 6 , its status increases, whereas when the accumulated satiation of a cow is less or equal to 3 , its status decreases.

\section{Details for cattle predation by lion}

The predation module was entirely re-designed during workshops. This module is applied at the level of a grazing area. To allow comparison of the role-playing game sessions, the randomness assigned to this process was eliminated by pre-defining the occurrences of cows being killed by a lion in the forest. Numbers are given in table 2 .

\begin{tabular}{lc}
\hline $\begin{array}{l}\text { GrazingAreas in the forest } \\
\text { Occurrences of presence of cattle in the subarea } \\
\text { area at which a kill will be considered }\end{array}$ \\
\hline Nearby forest $(\mathbf{F 1}, \mathbf{F 4}, \mathbf{F 7})$ & 3814 \\
\hline Middle forest (F2, F5, F8) & 2591216 \\
\hline Deep forest (F3, F6, F9) & 124679111214 \\
\hline
\end{tabular}

Table 2. Predefined timing for cattle predation by lion.

In the nearby forest, every 5-6 times some cattle will be there, a kill by the lion is considered. In the middle forest, the periodicity is decreased to every 3-4 times, whereas in the deep forest, the periodicity is set to every 1-2 times. The frequency of grazing and the distance to the forest's edge are therefore the two factors taken into consideration to trigger the event "lion's kill" in the forest. Once such a kill is considered, its actual realization depends on the presence of herdboys. When all cattle are guarded by a herdboy, the probability that the kill fails is $2 / 3$. Otherwise, the kill will occur and it is 30 times more likely to happen to a nonguarded cow than to a cow being guarded.

\section{Details for forage level in grazing areas and water levels in water pans}

These two modules rely on tabulated functions. The forage level of each grazing area is updated at the end of each month according to: (i) the month, (ii) the rainfall of the current month, and (iii) the number of cows that grazed during this month. Furthermore, a specific 
function was designed for each climatic year (Fig.11 and Fig.12). An additional feature was decided during the co-design of the model: the four communal grazing areas $(\mathrm{C} 1, \mathrm{C} 2, \mathrm{C} 3$ and C4) would never reach the "good" level of forage, but would remain "medium" at best.

The size of the water pans is also updated at the end of the month. It is not influenced by the number of cows drinking, but relies on a tabulated function designed according to monthly rainfall (Fig. 11 and Fig.12).

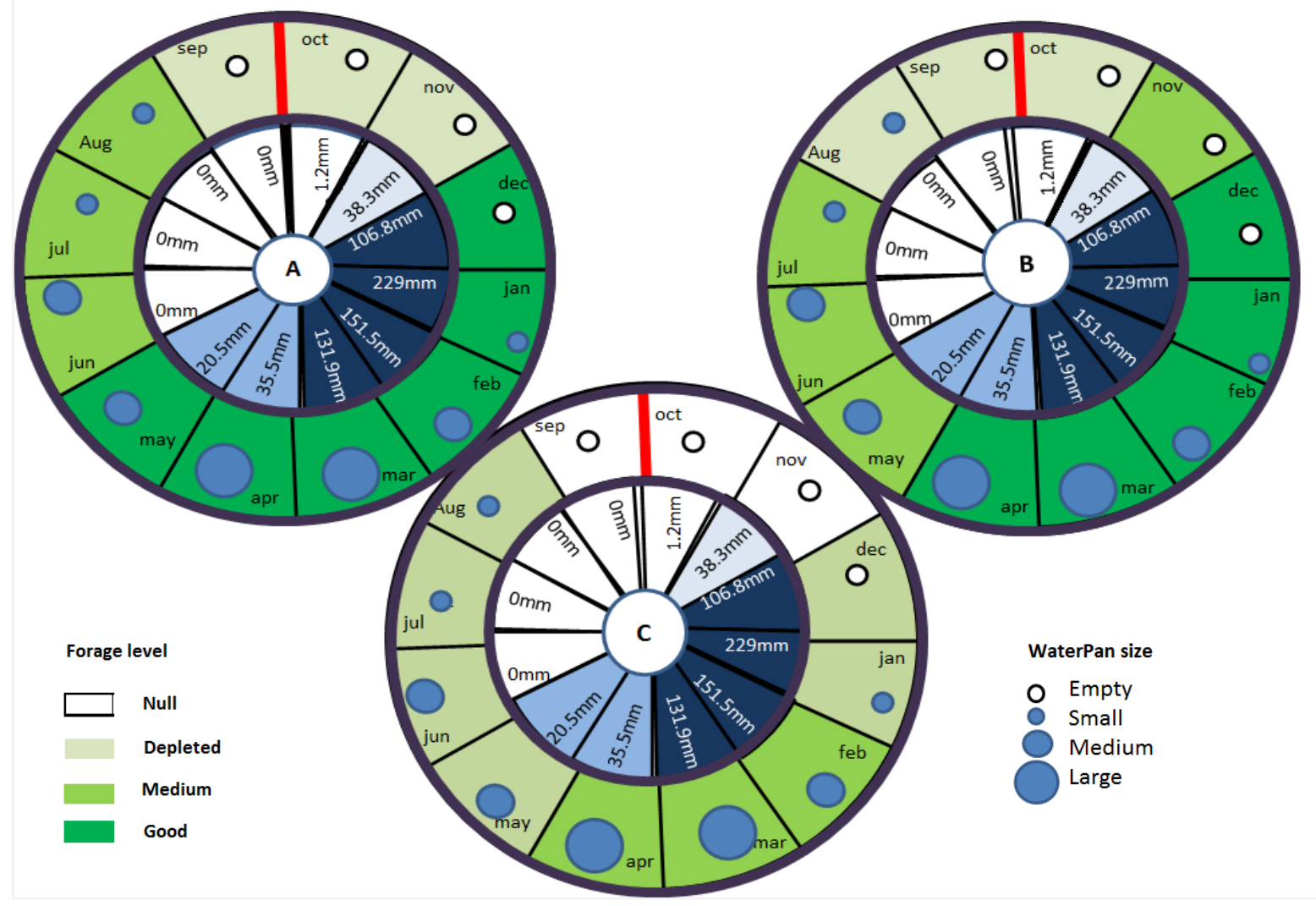

Figure 11. A representation of the tabulated function controlling the forage level of grazing areas and the size of water pans for the "Good Rain" year. The three diagrams represent the forage level at the end of each month in a given grazing area according to the number of cows grazing during the month. A: no cow grazing; B: between 1 and 10 cows; C: more than 10 cows. The circles in each month represent the size of water pans. Monthly rainfall is given on the inner wedges. 


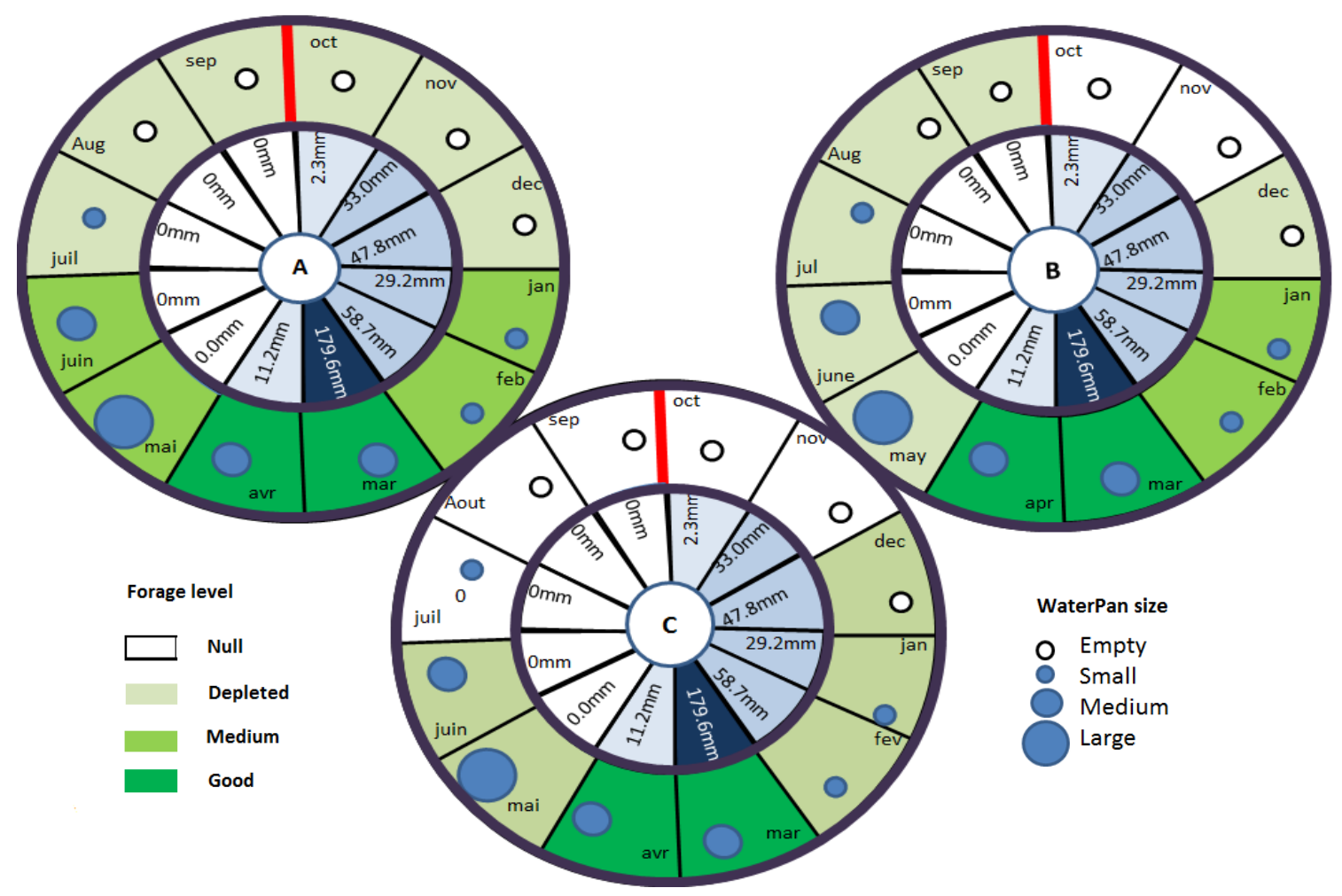

Figure 12. A representation of the tabulated function controlling the forage level of grazing areas and the size of water pans for the "Bad Rain" year. The three diagrams represent the forage level at the end of each month in a given grazing area according to the number of cows grazing during the month. A: no cow grazing; B: between 1 and 10 cows; C: more than 10 cows. The circles in each month represent the size of water pans. Monthly rainfall is given on the inner wedges.

\section{Choice, design and parametrization of the modules}

All modules were either collectively designed, or proposed by researchers and modified/validated by the other members of the team. The testing of each module was done through the co-design process. Each version of the game was tested (played) by the team, collectively discussed and modified/validated. 